NBER WORKING PAPER SERIES

A STRATEGIC THEORY OF INFLATION

Mordecai Kurz

Working Paper No. $\underline{379}$

NATIONAL BUREAU OF ECONOMIC RESEARCH 1050 Massachusetts Avenue

Cambridge MA 02138

August 1979 
A strategic mechanism of price adjustment is introduced to explain inflations in the U.S. during 1909-1974. The mechanism follows from our theory that when the profit rate is above a normal-target rate, competitive forces operate to lower prices while if the profit rate is below the target a correlated strategy among firms operates to generate a rise in prices as a strategy to improve profitability. The notion of "correlated strategy" is adopted from game theory. The mechanism may operate in harmony or against demand and the net effect is what we call the "basic inflation." Contrary to a-priori notions of positive association between inflation rates and profit rates, our theory proposes a critical test of a negative association between these variables. Such a relationship is in fact empirically established.

The analysis shows that large and persistent inflationary pressures are generated by low profitability and during 1971-1977 those accounted for some $20 \%-50 \%$ of total inflation. These pressures would be present even if no increase in cost occurs. This suggests that an important cause of the 1970's inflation is the low profit rate in the private sector and any public policy against inflation will fail if it does not aim at the same time to raise the profit rate on private capital.

Professor Mordecai Kurz Institute for Mathematical studies in the Social Sciences Encina Hall, Fourth Floor Stanford University stanford, CA 94305

415/497-2220 


\section{A STRATEGIC THEORY OF INFLATION *}

by

Mordecai Kurz

\section{Introduction}

The inflation-unemployment configurations of the 1970's have created a gap in contemporary macro-economic thinking. The "Phillips Curve" (see Phillips [1958], Lipsey [1960] and Perry [1964] for the U.S.) was rejected as a basic analytical and policy tool and with it the validity of an extensive body of modern thought became questionable. This has left wide open the task of explaining the observed relationship between unemployment and inflation.

$$
\text { Without aiming to review the "Phillips Curve" episode it is }
$$
relevant to this paper to clarify some aspects of why this analytical tool led to unsatisfactory results. To do this we recall that the Phillips curve was developed as a relationship between $\dot{w}(t) / w(t)-$ the rate of change of nominal wages and $u(t)$-the rate of unemployment. This equation can be written as

$$
\frac{\dot{w}(t)}{w(t)}=\Phi_{w}\left(u(t), x_{w}(t)\right)
$$

where $\left.x_{w}(t)\right)$ are "other" variables in the wage equation. Although in many contributions it is not always explicit what the interpretation *This research was partly supported by the National Bureau of Economic Research and partly by the National Science Foundation Grant SOC75-21820 at the Institute for Mathematical Studies in the Social Sciences at Stanford University. It appears jointly as an NBER working paper and IMSSS technical report. The author wishes to thank his assistant Kenneth Lutich for dedicated assistance and many discussions which contributed substantially to this paper. He also thanks Steven Galatis for his help.

The research reported here is part of the NBER's research program in social insurance. Any opinions expressed are those of the author and not those of the National Bureau of Economic Research. 
of the Phillips curve is, it should be clear that it represents an equilibrium condition in the labor market (see, for example, SamuelsonSolow [1960], Tobin [1972] and Friedman [1970], [1971]).

In many of the uses of the Phillips curve a relationship is derived between the rate of inflation and the rate of unemployment. To accomplish this a price determination equation is postulated and this is usually a model based on full-cost pricing. A typical such equation can be found, for example, in Perry [1966] and is defined by

(1.2) $\frac{\dot{p}(t)}{p(t)}=\alpha_{0}+\alpha_{1} \frac{\dot{w}(t)}{w(t)}+\alpha_{2} \frac{\dot{p}^{r}(t)}{p(t)}+\alpha_{3}\left(\frac{Q(t)}{K(t)}\right)+\alpha_{4} \Delta\left(\frac{Q(t)}{K(t)}\right)$

where

$$
\begin{aligned}
& p^{r}(t)=\text { price of raw materials at } t \\
& \frac{Q(t)}{K(t)}=\text { an index of capacity utilization at } t .1 /
\end{aligned}
$$

One usually interprets equation (1.2) as an equilibrium condition in the commodities markets resulting from excess demands in these markets being equal to 0 .

Now in order to obtain the relation between $\dot{p}(t) / p(t)$ and $u(t)$ one inserts (1.1) into (1.2) in order to obtain

(1.3) $\frac{\dot{p}(t)}{p(t)}=\Phi\left(u(t), x_{p}(t)\right)$

where $x_{p}(t)$ are "other" variables. Since $\dot{p}(t) / p(t)$ as well as $\dot{w}(t) / w(t)$ and $u(t)$ are all endogenous variables, one thinks of (1.3) as a relation between the equilibrium values of the two endogenous variables. 
This relationship depends both on the "other" variables as well as the random shocks to the system as a whole.

We now note that the "trade-off" between $\dot{p}(t) / p(t)$ and $u(t)$ as specified in equation (1.3) can be incorrectly specified due either to incorrect specification of the Phillips curve (1.I) or the price formation equation (1.2). Thus the failure of the empirical relation (1.3) in recent years may be due to either one of these factors. Although we do not believe that equation (1.1) provides a correct specification of the equilibrium condition in the labor market, we shall not study this relationship between $\dot{w}(t) / w(t)$ and $u(t)$ in the present paper. Instead, we concentrate here on the price formation mechanism (1.2), which we believe is an important ingrediant in understanding the process of inflation, and propose in this paper a reformulation of the mechanism (1.2). More specifically, in developing our strategic approach to inflation we shall regard firms as adopting equilibrium strategy of price adjustment and equations type (1.2) will provide the equilibrium quantitative description of this strategy.

A word may be in order about cost-push and demand-pull theories of inflation. The attempt to establish a causal relation between cost and inflation or demand and inflation would involve the same set of problems discussed earlier with regard to the Philips curve: cost, demand and inflation rate are all endogenous variables and without a theory of inflation which will define the structural relations among them no useful causal interrelationships can be discussed. $2 /$ With this reservation made, 
we shall argue below that the cost-push demand-pull distinction may have a classificatory value which is useful. The strategic theory of inflation which we develop here will regard the decision to change prices as an endogenous decision with explicit structural description. At different times a decision to raise prices comés either in . response to increased cost or increased demand and then it looks like a cost-push or demand-pull inflation. However, the theory will explicitly state the circumstances in which despite rising cost, the endogenously determined rate of inflation. will be less than the corresponding rate of rising cost and perhaps even negative when cost is rising. Furthermore, circumstances may be specified in which high demand may be associated with either rising or declining prices and in the same way low demand may be associated with either rising or declining prices. In this sense one can use the cost-push demand-pull characterization as a classificatory tool of inflationary processes and with that aid the understanding of the deeper structural explanation of inflation.

A final introductory note must be related to the methodology of analyzing inflation. In the context of a general equilibrium system. of market clearing any process of rising prices must be induced by excess demand causing the "auctioneer" to raise prices. From this view point the study of inflation must necessarily be the study of those causes making for general excess demand in all markets which would then cause the "auctioneer" to raise all prices. When looked at from the auctioneer's view point the deeper issues cannot be uncovered since many situations 
appear to lead to contrasting conclusions: we have many periods of recession about which we may think as periods of excess supply in which prices do rise and we also observe periods of recovery with high and perhaps excess demand when prices are stable or even falling. What one discovers is that even in periods of recession a situation of excess demand may develop in commodity markets and this may lead to rising prices. This can be caused by the decision by firms to lay-off workers, reduce output and cut back the supply to avoid losses. This suggests that there may be circunstances in which price targets may be set and supplies adjusted to them. This would lead to the conclusion that recessions, in which demand falls, are not necessarily periods of de-facto excess supplies and recoveries are not necessarily periods of de-facto excess demand. With this in mind one may conclude that studying inflation as a process in which the auctioneer raises prices in response to excess demands is probably not a fruitful way of looking at the problem. We propose that the study of inflation must shift attention back to the behavior of firms who make the market. Furthemore, one must look at inflation as a state in which all firms elect to raise prices as a rational choice in the given environment. Such a theory will need to concentrate on those factors which induce all firms to adopt similar optimal price change strategies. Inflation, in this context, is an equilibrium strategy adopted by all firms to achieve whatever goals they cannot achieve without the inflationary strategy. 
2. Competition, Normal Profits and Correlation of Strategies

2.a Competition and Correlation of Pricing Strategies

We view our competitive firm as operating in a dynamic environment and aiming to maximize its long term profits by selecting eptimal output, investment and pricing strategies. The idea of the firm as a long run profit maximizer is well known and a similar view was adopted by many writers (see, for example, Modigliani [1958] and [1977, pages 6-8]). What we shall do here is develop this hypothesis in a strategic context of an indefinitely repeating economy and carry out an empirical test of the approach.

An optimal long run profit maximizing strategy is different from short-term strategy in the fact that the firm must take into account at any date $t$ not only the state of the world at later dates but also the future response of the competitors to its currently chosen actions (at $t$ ). This means, for example, that if a firm lowers its prices at $t$ it must take into account the possible retaliation of its competitors both at the present and also in all future market dates. In a one-period static world no such considerations need be taken into account since any strategy adopted by all participants has a duration of one market period only. It then follows that the essential. nature of a long-term strategy hinges on the fact that the economy repeats itself indefinitely often and the market, so to speak, reopens every "morning" or cven continuously. As long as we have a finite number of firms there does not exist a natural notion of a "small" firm whose strategy may be ignored by the others. $3 /$ This means that 
regardless of how small, in the context of a repeated econom, the strategy of each firm must be considered by all others and an equilibrium will consist of a set of optimal long-run strategies adopted by every firm taking into account the strategies adopted by all the other firms. The repetition of the economic game enables a great deal of information to pass implicitly among the participants. This is done simply through a complex structure of signals which enables the participants to learn all they need about each other and thus to coordinate their strategies. This situation has often been viewed as "implicit collusion" and thus long-term profit maximization was regarded by Modigliani [1958] as a reflection of oligopolistic behavior. This conclusion is not necessary since even in a perfectly competitive economy with a finite number of firms implicit coordination of strategies may occur and such coordination does not require a "small" number of participants.

The idea of coordination as resulting from the repetitive nature of the economy has received significant attention in Game Theory (see for example, Aumann [1959], Kurz [1977a], Gerard-Varet and Moulin [1978] and others). The notion used in Game Theory is one of "Correlated Strategies" applicable in non-cooperative games of conflict which are repeated. Here the participants cannot make binding contracts (Iike in the famous "prisoner's dilema") but overcome this non-cooperative limitation by adopting modes of behavior, or strategies, which signal their desire for cooperation. The repetition of the game provides ample opportunities both to test the sincerity of those who signal a desire for cooperation and also to 
retaliate against those who may double-cross the "honest" participtants. Thus in an indefinitely repeating game a "correlated strategy" could constitute an equilibrium which looks as if it were a result of a completely collusive process. The stability of such an equilibrium is derived from the constant threat of retaliation by all the participants against a deviator from the adopted correlated strategy. Such a retalia-. tion may be applied immediately and could continue into the indefinite future. An important conclusion which must be derived from this theory is that the extent to which correlated strategies may be adopted depends upon two essential elements: the perceived gain which can potentially be enjoyed by all the players and the punishment-retaliation 4 / ability of the participatns against any deviator.

As long as free entry to an industry is available the establishment of implicit collusion or "correlated strategy" in competitive markets do not turn them into oligopolies. However, let us consider for a moment the effect of fixed entry or exit cost on the nature of the equilibrium. If there are no such costs then a correlated pricing strategy may create temporary abnormal profits but free entry with zero fixed entry and exit cost will keep expanding output and push the profit rate down towards its normal level. Thus with zero entry and exit cost the retaliation ability of the participants is restricted to the gain from correlation. This can be significant if the profit rate is below normal and correlated pricing strategy may prevent it from getting even lower. This means that when the profit rate is above normal the process of free entry and the expectations that the profit rate cannot stay 
abnormally high will act against the formation of correlated pricing strategies and is likely to result in competitive price cutting. However if the profit rate drops below normal due to an unexpected rise in cost or some other factor, the industry will obviously attempt to make technological or organizational adjustments to improve its profitability and some firms may leave the industry. However in addition to these normal competitive adjustments, forces will be set in motion for the formation of a correlated price increasing strategy and due to this strategy the profit rate will not be as low as it might be. Due to the fact that in this case there is no entry and exit cost, the retaliation ability of the participants against a deviator is derived only from the fact that such a correlated strategy is beneficial to all and a deviation will prove harmful to all.

A more complex case arises when significant entry and exit costs are present. We note that in our reality of imperfect information and irreversible investments such costs could be prohibitive. They include all dimensions of set up cost: legal, financial, locational, labor and managerial training, but also all irreversible investments. These include informational development, product advertising, community and public relations and finally all the cost of specific plant and equipment which cannot be transfered costlessly to other industries. In many industries a significant part (if not all) of total investments falls in these specific categories.

With fixed entry and exit cost a correlated pricing strategy in a repeated economy provides the participants a significant retaliatory 
tool. This may be used against any new entry or against any deviator from the accepted pricing policy. Since drastic price cutting can result in widespread losses which cannot be recovered due to the specificity of the investments, such circumstances would have two consequences: first, no new entry will occur before the profit rate goes above a certain level which would provide compensation for the risk of entry. Second, correlated strategies are more likely to be established and have a more stable character due to the high cost, to all the participants, of a breakdown in the coordinated activity. We can thus conclude that correlated pricing strategies are more likely to be formed the lower is the profit rate and the higher are the costs of entry and exit.

\section{2.b The Normal Profit Rate}

The establishment of a correlated pricing strategy is conditional upon the existence of a well defined set of signals which are clearly understood and the interpretation of which is commonly agreed upon. We proposed above that the position of the actual profit rate $R(t)$ in relation to the target profit rate $R^{*}(t)$ is crucial to this signalling process. But what is the normal target profit rate $R^{*}(t)$ ? Since this concept is one of the key ideas of this work we must clarify its meaning.

We are assuming that given the technological conditions of the economy, the political and legal foundations of property rights, the availability of resources and the functioning of our institutions 
there is a target after-tax profit rate $R^{*}$ which may be designated $R^{*}(t)$ which may change over time due to the change in exogenous conditions. Similarly there is a distribution of profit rates $R_{j}^{*}(t)$ over industries depending upon-the risk level, the stage of technological development, the cost of entry and exit and other characteristics. The after-tax profit rate $R^{*}(t)$, with its associated industrial distribution $R_{j}^{*}(t)$, is viewed as a target rate which firms in the various industries believe they can earn and will ultimately earn after they have selected their optimal decision rules and made all the technological and administrative adjustments needed to improve their profitability. The actual aftertax profit rate $R(t)$ may be above $R^{*}(t)$ or below $R^{*}(t)$ and the temporary relation between them may reflect all the random elements in our economic universe in addition to other unexpected factors. The latter may include sudden changes in the tax laws, unexpected rise in labor or other input cost, unexpected change in the political environment resulting in legal restrictions on the activities of the firms and other restrictions like environmental requirements which may demand capital investments and adjustment time. The belief in $R^{*}(t)$ can be explained in two separate ways which are complementary. The first explanation may concentrate on the long term supply of capital and the rate of technological progress. These could have combined in modern time to create excess supply of goods and capital when the profit rate goes above $R^{*}(t)$ and excess 
demand when it goes below $R^{*}(t)$. Thus based on historical facts it is perfectly rational to expect the economy to return to it.

To justify this view consider in Diagram 1 a plot of the after tax gross and net rates of return on capital in the U.S. 1909-1974. The mean value are $\bar{r}_{\mathrm{g}} \frac{5}{}=5.4 \%$ and $\bar{r}_{\mathrm{n}}=4.2 \%$. Note that the gross rate demonstrates no trend and the major fluctuations in this rate are due to such unexpected factors as wars and the depression. The very slight downward trend in the net rate is probably due to the tax treatment of depreciation.

A second interpretation of $R^{*}(t)$ can be only sketched here. It will start from the hypothesis that both the tax rate and the after-tax wage rate and rate of return on capital--all are outcomes of the political and economic balance of power in our society. Such a.

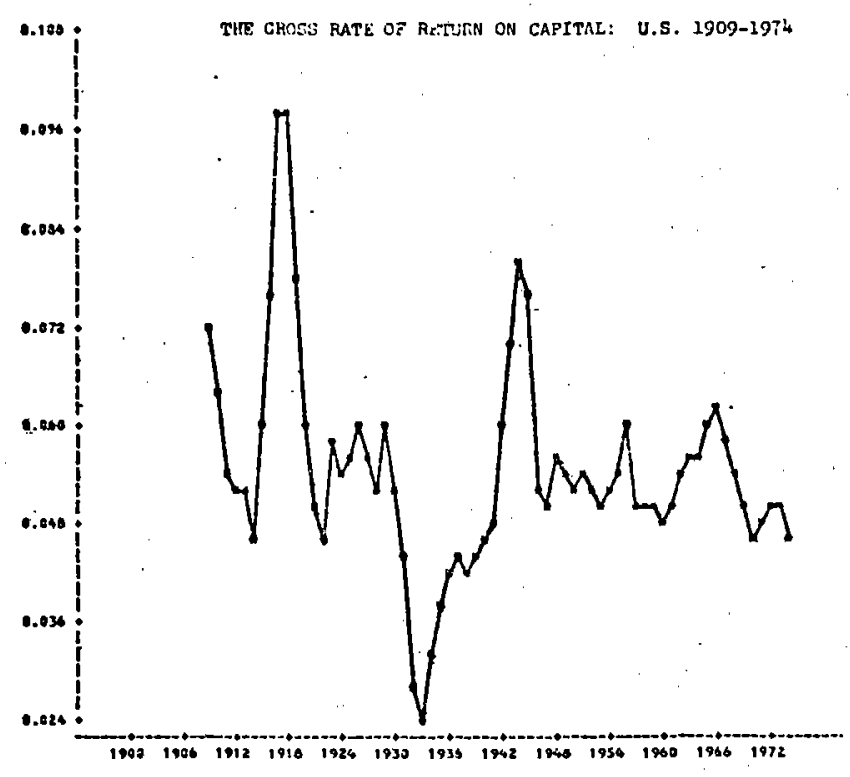

rees

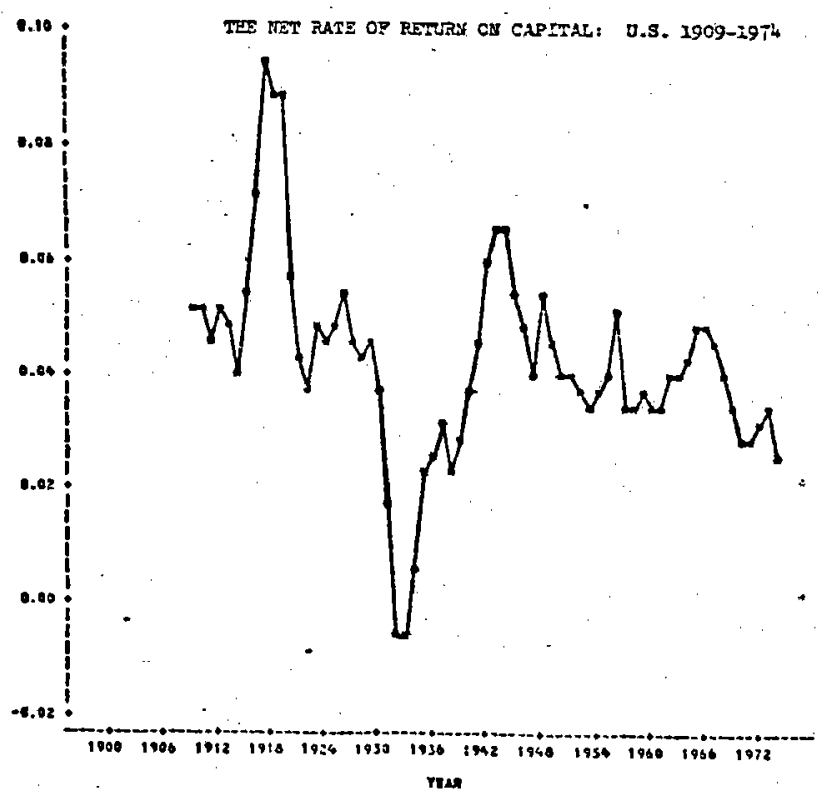

Diagram 1 
balance of power is reflected in the constitutional rights of the various economic agents. Thus the target profit rate $R^{*}(t)$ is simply a reflection of all the economic options constitutionally available for the employment of private capital. Since the constitutional rights of the agents have changed little during the 20-th century, the rate of return has not changed either. We may note, however, the distinct decline in the rates between 1966 and 1974 .

2.c The Formation of Pricing Strategy: The Basic Hypothesis Given the target profit rate $R^{*}(t)$ the firm can define the normal price $p^{*}(t)$. In Diagram 2 below we plot $A^{*}$--the average

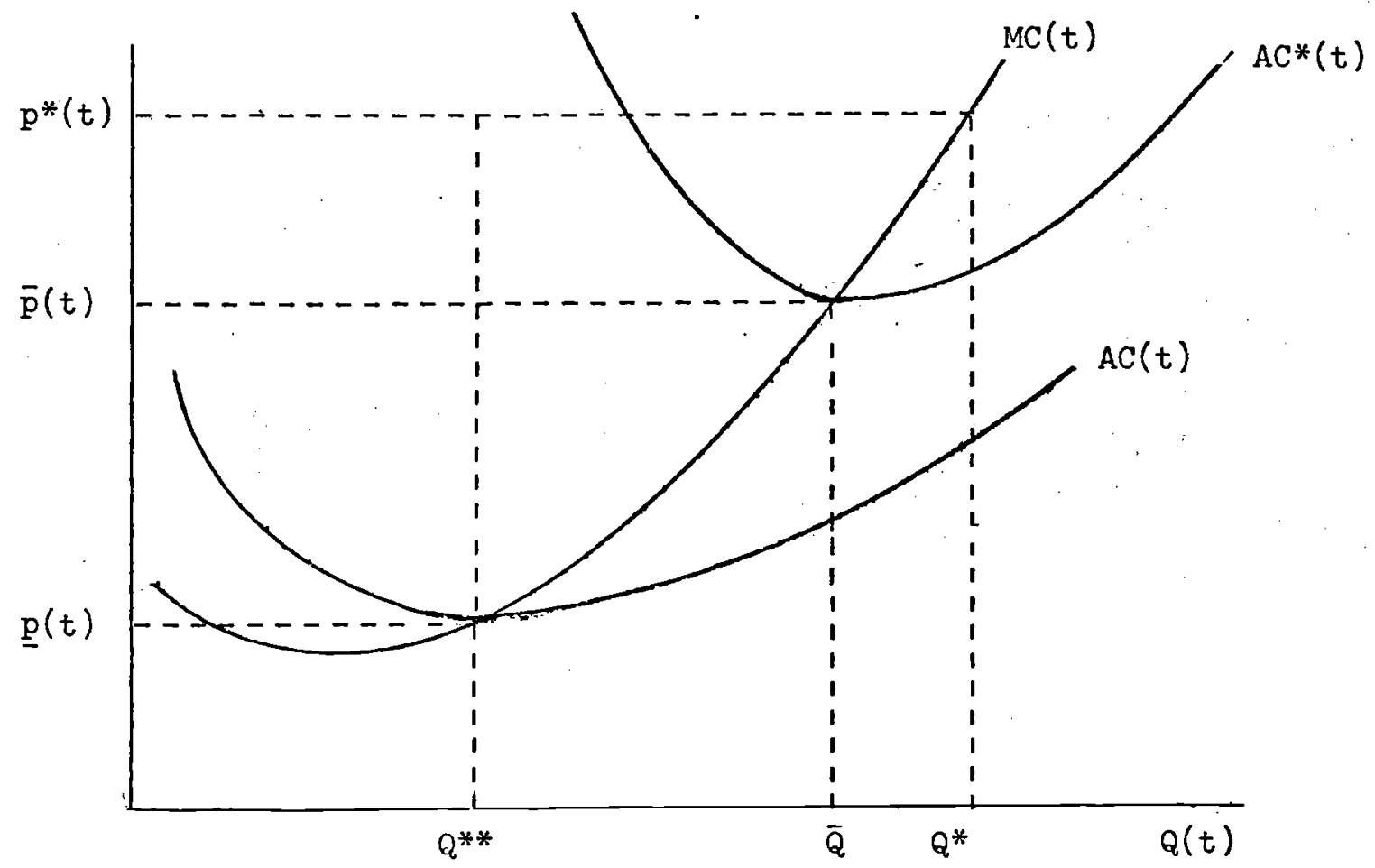

D1 agram 2 
cost curve with $R^{*}(t)$ built into the cost function and $A C$--the average cost function associated with a 0 profit. In a completely stationary environment the strategy of the firm is based on the expectations that $p(t)$ should be equal to $\vec{p}(t)$ and output equals to $\bar{Q}$. A long term equilibrium will in fact determine the number of firms which will operate in the industry. Due to fluctuations in productivity and variations in prices of inputs, the curves $\mathrm{AC}^{*}(t)$ and $A C(t)$ move and the firms continuously adjust product prices so as to respond to these changes. This means that product price adjustments come about in response to actual or expected changes in profitability: any actual decline in the profit rate or an expectation for a future decline based on observed rise in cost initiate the forces which will establish a correlated price increase strategy. Sudden increases in demand may accelerate the price adjustment process and declines in demand may slow but not stop it since the process is initiated by long term considerations rather than the temporary condition of demand. This means that variations in demand may complement or slow down the basic pricing strategy initiated by conditions of profitability while part of the changes in demand will be translated into changes in output level and to changes in the number of firms in the industry rather than changes in prices. We return to this key observation below.

If the industry were operating under short term profit maximization, changes in demand would have caused prices to fluctuate above $\underline{p}$ since below this price many firms would close dow rather 
than produce. Under such short term profit maximization, we have a very simple price strategy:

$$
\frac{\mathrm{W}(t)}{\mathrm{p}(\mathrm{t})}=\text { marginal product of labor } \text {. }
$$

There are a few arguments why we do not follow this approach and these we discuss now:

(i) The observed facts are that fluctuations in output are more extensive than fluctuations in prices. This suggests that the long term strategy of firms is to select the price $p^{*}(t)$. such that as long as demand fluctuations stay within say $Q^{*}$ and $Q^{* *}$ output will be adjusted but prices will remain constant resulting in a mean profit rate of $R^{*}$. However if the cost functions move so that a mean rate $R^{*}$ cannot be attained then prices will be adjusted. The most important changes in the cost curves are caused by changes in taxes, productivity and prices of inputs. Furthermore, if demand expands beyond $Q^{*}$ firms will either allow shortages to develop or expand capacity. This is essentially the Keynesian outlook on the problem and is shared by such writers as Patinkin [1965] and Tobin [1972].

(ii) In an industry where price strategies are correlated, every participant is reluctant to lower prices since he might invite retaliation by the other suppliers. 
Given that it takes time to establish a correlated strategy, each producer would rather allow small fluctuations in demand to translate into small variations in output.

(iii) Changing the labor force so as to equate the short term marginal cost of labor to the wage rate entails extensive long term cost. First it creates both the cost of recruiting and also the risk of not being able to obtain the best workers when the demand for labor expands. But more important is the fact that by shifting all the risk of fluctuations in demand to labor, the firm invites long term hostility and retaliation by labor. By providing its labor force somewhat greater job security the firm attains industrial tranquility at the cost measured by the difference $p^{*}-\bar{p}$. which is the amount needed to pay for this insurance cost. The firm can also diversify its investments and thus indirectly reduce the needed premium $p^{*}-\bar{p}$. This idea of the firm providing the insurance is fundamental in the "Labor Contracts" J.1terature (see Azariadis [1975], [1978], Baily [1974], and Gordon [1974]). According to this approach if workers are risk averse while firms are risk neutral then optimal collective bargaining contracts would favor rigid wages and fluctuating employment. In such an environment lowering prices without lowering wages could be used only as a 
short term device to get rid of excess inventories and these appear to be the observed facts.

Having rejected the idea of a rigid short term profit maximization strategy. we propose, as the basic hypothesis of this work that the profit gap $\left[R^{*}(t)-R(t)\right]$ - is the basic cause for the formation of correlated pricing strategy. The rest of this section will clarify this hypothesis and for that purpose we shall divide the discussion into two parts: the first case of $R(t)>R^{*}(t)$ and the second case of $R(t)<R^{*}(t)$.

\section{Case 1: $R(t)>R^{*}(t)$}

In this case the temporary price established in the industry is $p(t)>p^{*}(t)$. It is important to keep in mind that firms are price takers but the nature of their price taking depends upon how firmly a correlated price strategy is established. Under the present circumstances of abnormal profits there is little chance for a success of correlation of strategies since there are two forces operating in the market: the first is some expansion of capacity through new entries into the industry and further build-up by those in the industry. The second, and more important factor, is the realization by all firms that the abnormal profits cannot last very long and there is insufficient time to establish a correlated pricing strategy thus each firm would want to use the transition period to expand its market share. Competition, therefore, will prevent the establishment of correlated pricing strategy and cause $p(t)$ to gradually fall relative to the cost defining $\mathrm{AC}^{*}$. 
In the circumstances at hand the decline in the relative price may simply take the form of slow or no price increases when costs are rising unless major declines in demand are experienced. This is so since in principle firms are reluetant to lower prices since changes are important signals in an environment in which a correlated price strategy is potentially in effect. Under such circumstances price cutting may be interpreted as the unwillingness of a firm to follow a price raising strategy when the environment will justify it. Furthermore keeping prices reasonably stable when costs are rising becomes a positive signal that when in the appropriate environment, the firm will join a correlated price raising strategy.

Case 2: $R(t)<R^{*}(t)$

When the profit rate is below target and $p(t)<p^{*}(t)$ firms know that the danger of new entry is minimal and attempts will be made to establish strategies to raise prices. This is not a simple matter since for a correlated strategy to function all firms have to recognize that $r(t)<r^{*}(t)$ and this takes time. Furthermore since no firm would wish to lose its market share the movement from $p(t)$ towards $p^{*}(t)$ will be slow particularly since $p^{*}(t)$ is moving through time. The critical observation which we make can be stated as follows:

The lower is $R(t)$ relative to $R^{*}(t)$ the greater is the incentive of all firms to cooperate and ad- 
here to a correlated strategy of raising prices and

the more rapid will be the rate at which prices will

be raised toward $p^{*}(t)$.

Note that in Diagram 3 when $p(t)<p^{*}(t)$ the firms may be operating at a level of say $q^{l}$. If the price is raised to $p_{2}(t)$ the firm may retain the lower output $q^{2}$ with a much improved profit margin $6 /$ on its capital stock. When $R(t)<R^{*}(t)$ for the industry, some firms may elect to lower their capacity or leave the industry rather than sustain the lower profit rate. Those who stay and improve their profitability by raising prices may be viewed as price takers in the sense of adhering to a fixed strategy of raising prices which will be followed by all. An interesting theoretical work would

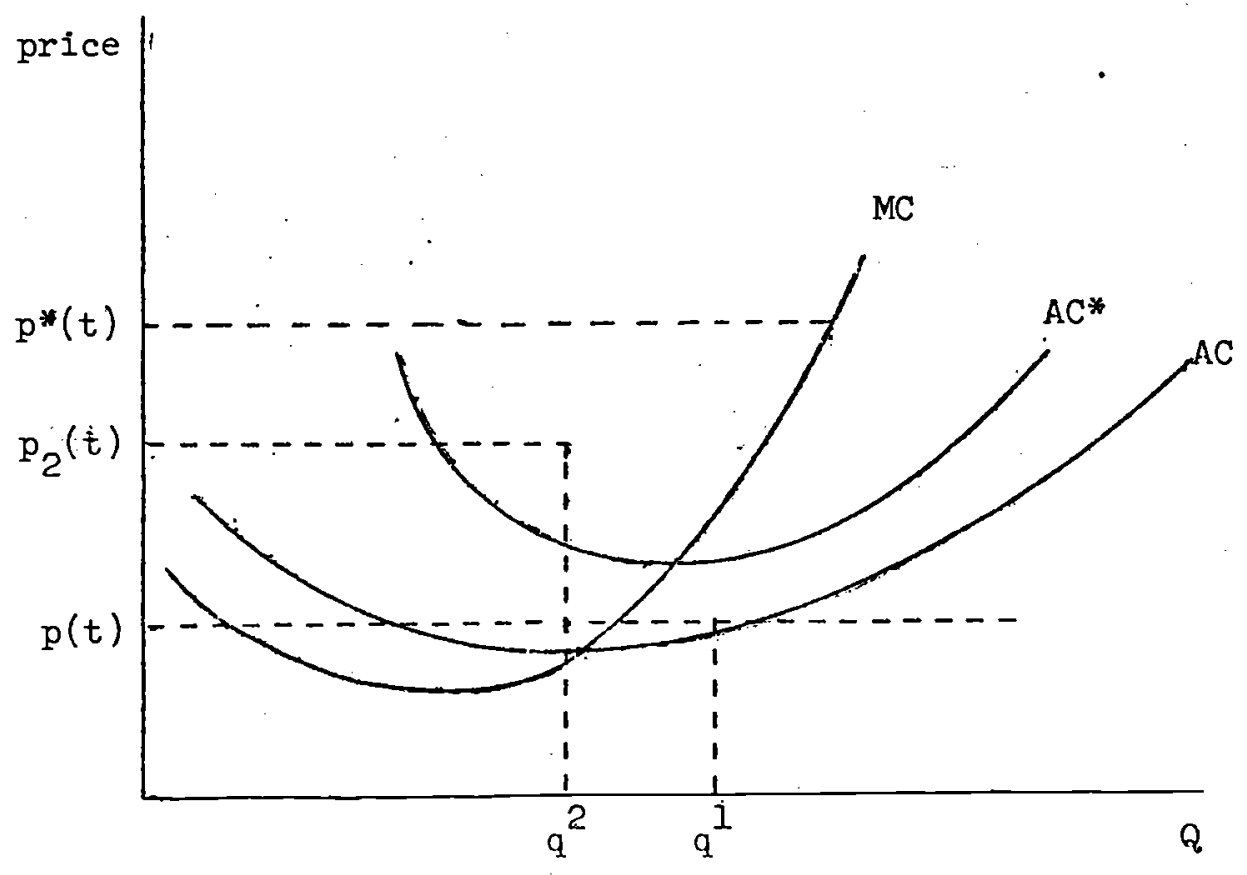

Diagram 3 
construct a model like the one we are describing here and derive the equilibrium strategies which will be followed under alternative condi-. tions of the profit gap $\left[R^{*}(t)-R(t)\right]$. Here we shall treat this as the key empirical question to be resolved by the data and such a formulation will be presented in the next section.

We can thus conclude the description of our hypothesis by specifying its two components:

(1) For fixed level of productivity and input prices the larger is the profit gap $R^{*}(t)-R(t)$ when $R^{*}(t)>R(t)$, the more likely it is that a correlated strategy of price increase will be formed and the faster would prices be raised.

(2) Apart from the actual profit gap firms will consider the potential or predicted profit gap due to rising cost relative to productivity. Our hypothesis is that the more negative this gap becomes the more likely is a correlated strategy to form and the more rapidly would prices be raised.

Again we need to emphasize that a firm adhering to a correlated price strategy is a price taker. Clearly what is the mechanism for actually raising prices and who is the first who raises prices is besides the point. The mechanism may be based on some random process in response to which all would raise prices; or the price increase may occur in response to a rise in the price of some input which will, 
somehow, trigger a product price above what can be explained by the rise of cost. With this in mind it is useful to examine the relationship between our "Basic Hypothesis" and the cost-push demand-pull explanations for inflation.

Perhaps the simplest way of putting it is to say that our hypothesis implies that holding all other factors constant a higher inflation rate is caused by lower profitability. Thus there are two important implications to be kept in mind:

(i) If a rise in cost occurs it will be associated with more than a proportional increase in prices when profitability is low and less than a proportional increase in prices when profitability is high. When the profit rate is high, rising cost may even be associated with actual lowering of prices.

(ii) If a high level of demand occurs, it will complement the pressure on rising prices when profitability is low but could be associated with declining prices when profitability is high. Thus, apart from extensively unexpected demand due to such factors as wars, the rate of price change when demand fluctuates depends upon the rate of profits. However, since recessions (thus low demand) are sometimes associated with low profit rates, our Basic Hypothesis suggest that inflationary forces may be operating during periods like this even if there is insufficient aggregate demand to support it. 
This suggests to us that the classification of inflations should be made to depend upon the rate of profit in the sense that when $R(t)<R^{*}(t)$ profitability factors may be stronger while when $R(t) \geq R^{*}(t)$ "demand-pull" factors may dominate

The reason for the above classification is that when $R(t) \geq R^{*}(t)$ then atomistic competitive forces operate and large shifts in demand could cause price changes. If, however, $R(t)<R^{*}(t)$ then fluctuations in demand have far less influence on price changes. In this environment a correlated price strategy will usually respond, to any cost increases by raising prices more than cost in order to close the profitability gap. We shall refine this classification below.

A very important dimension of our theory is found in its provision of a critical test to distinguish it from the conventional. static model of price formation. The usual "auctioneer" model of price formation predicts that excess demand results in both rising profits and prices thus establishing a positive association between the rate of inflation and the rate of profit. Our approach proposes the opposite: a negative association between the rate of inflation and the rate of profits. This crucial test will be evaluated below.

3. The Basic Hypothesis and Econometric Specifications

3.a Specification of the Basic Hypothesis

Our "basic hypothesis" stated earlier decomposes the strategy into two components: 
(i) the effect of the profitability gap on price changes

(ii) the effect of the expected change in the profitability gap if prices are not altered.

This hypothesis can be expressed in its simplest linear form by an equation like

$$
\frac{p(t)-p(t-1)}{p(t-1)}=\alpha\left[R^{*}(t-1)-R(t-1)\right]+\beta\left[E_{p}(R(t))-R(t-1)\right]
$$

where

$$
\begin{aligned}
R^{*}(t-1)= & \text { the normal-target profit rate which firms believe } \\
& \text { they could potentially earn in } t-1 \\
\mathrm{R}(t-1)= & \text { the actual profit rate at } t-1 \\
E_{p}(R(t))= & \text { the expected profit rate in } t \text { given that product prices } \\
& \text { are not changed }
\end{aligned}
$$

The rest of this section is devoted to the development and elaboration of equation (3.1) above.

Starting with the primitive concept of $R(t-1)$, it is defined by

$$
\begin{aligned}
R(t-1)= & (1-\tau(t-1)) \frac{p(t-1) Y(t-1)-w(t-1) L(t-1)}{p_{k}(t-1) K(t-1)} \\
& +\pi_{k}(t-1)
\end{aligned}
$$


or with

(3.2a) $r(t-I)=(I-\tau(t-I)) \frac{p(t-I) Y(t-I)-w(t-I) L(t-I)}{p_{k}(t-I) K(t-I)}$

We define

$$
R(t-I)=r(t-I)+\pi_{k}(t-I)
$$

where:

$$
\begin{aligned}
& \tau(t-I)=\text { the tax rate at } t-I \\
& p(t-I)=\text { price of output at } t-I \\
& Y(t-I)=\text { output Ievel at } t-I \\
& W(t-I)=\text { wage rate at } t-I \\
& L(t-I)=\text { labor input at } t-I \\
& P_{K}(t-I)=\text { price of unit of capitaI goods at } t-I \\
& K(t-I)=\text { capital stock employed at } t-I \text {. } I \text {. } \\
& \pi_{K}(t-I)=\text { the relative rate of capitaI gains at } t-I
\end{aligned}
$$

hence

(3.4) $\pi_{k}(t-1)=\frac{p_{k}(t-I)-p_{k}(t-2)}{p_{k}(t-2)}-\frac{p(t-I)-p(t-2)}{p(t-I)}$.

The 1 period lag in (3.1) is based on the idea that it takes time for a firm to know its exact level of profitability. In addition, in order for a correlated strategy to be successfully established 
firms will have to be convinced of the state of their own profitability as well as the state of profitability of all other firms in the industry. The profit rate of any given firm may fluctuate but a correlated strategy will be established only when all firms share the same environment.

In the application below we shall test models with 2 period lag and a Koyck model with a lag of infinite number of periods. Thirning now to $R^{*}(t-1)$ we shall assume that

(3.5) $\quad R^{*}(t-1)=r^{*}+\pi_{k}(t-1)$

where $r^{*}$ is a constant to be estimated. The justification for this assumption is based on the simple observation (see Diagram 1) that during the 20th century the post-tax rate of return $r(t)$ fluctuated around a constant and we shall take $r^{*}$ to be related to the long term mean value of $r(t)$. We thus can combine (3.5) and (3.4) to obtain

$$
\left[R^{*}(t-1)-R(t-1)\right]=\left[r^{*}-r(t-1)\right]
$$

To complete the exposition of equation (3.I) one needs to consider what would happen to the profitability of the firm if it did not change prices. Thus the expression $E_{p}(R(t))$ is the expected profit rate when all the variables under the control of the firm are held constant. More precisely this expression is defined as 
$(3.7)$

$$
\begin{aligned}
E_{p}(R(t))= & r(t-I) \\
& +\frac{\partial r(t-I)}{\partial w(t-I)}\left(E_{w}(t)-w(t-I)\right) \\
& +\frac{\partial r(t-I)}{\partial \tau(t-I)}\left(E_{\tau}(t-I)-\tau(t-I)\right) \\
& +\frac{\partial r(t-I)}{\partial p_{k}(t-I)}\left(E_{k}(t)-p_{k}(t-1)\right. \\
& +\frac{\partial r(t-I)}{\partial y(t-I)}(E Y(t)-Y(t-1)) \\
& +E \pi_{k}(t)
\end{aligned}
$$

Equation (3.7) says that $E_{p}(R(t))$ is equal to the profit rate from operations at $(t-I)$ (i.e., $r(t-I))$ plus the expected rate of relative capital gains $\left(E \pi_{k}(t)\right)$ less the change in the profit rate induced by changes in the wage rate, the tax rate, the cost of capital goods and productivity.

Now from (3.2) we can define

$$
\begin{aligned}
& \frac{\partial r(t-I)}{\partial w(t-I)}(E w(t)-w(t-I)) \\
= & -(I-\tau(t-I)) \frac{w(t-I) L(t-I)}{p_{k}(t-I) K(t-I)} \cdot\left(\frac{E W(t)-w(t-I)}{w(t-I)}\right) \\
& \frac{\partial r(t-I)}{\partial \tau(t-I)}(E \tau(t)-\tau(t-I)) \\
= & -(I-\tau(t-I)) \frac{p(t-I) Y(t-I)-w(t-I) L(t-I)}{p_{k}(t-I) K(t-I)} \\
& \cdot\left(\frac{E \tau(t)-\tau(t-I)}{I-\tau(t-I)}\right) \\
= & -\frac{r(t-I)}{I-\tau(t-I)}(E \tau(t)-\tau(t-I))
\end{aligned}
$$


$(3.8 c)$

$$
\begin{aligned}
& \frac{\partial r(t-1)}{\partial p_{k}(t-1)}\left(E p_{k}(t)-p_{k}(t-1)\right) \\
= & -(1-\tau(t-1)) \frac{p(t-1) Y(t-1)-w(t-1) L(t-1)}{p_{k}(t-1) K(t-1)} \\
& \left.=\frac{E p_{k}(t)-p_{k}(t-1)}{p_{k}(t-1)}\right) \\
= & -r(t-1) \frac{E p_{k}(t)-p_{k}(t)}{p_{k}(t-1)} \\
& \frac{\partial r(t-1)}{\partial y(t-1)}(E Y(t)-Y(t-1)) \\
= & (1-\tau(t-1)) \frac{p(t-1) Y(t-1)}{P_{k}(t-1) K(t-1)}\left(\frac{E Y(t)-Y(t-1)}{Y(t-1)}\right) .
\end{aligned}
$$

We think of the three variables defined in $(3.8 \mathrm{a})-(3.8 \mathrm{c})$ as three cost changes and (3.8d) as productivity change holding inputs constant. Combining (3.2), (3.7) and (3.8a)-(3.8d) we obtain

$$
\begin{aligned}
& {\left[E_{p}(R(t))-R(t-1)\right] } \\
= & {\left[-\left(1-\tau(t-1) \frac{w(t-1) L(t-1)}{p_{k}(t-1) K(t-1)}\left(\frac{E w(t)-w(t-1)}{w(t-1)}\right)\right.\right.} \\
& -\frac{r(t-1)}{1-\tau(t-1)}(E \tau(t)-\tau(t-1) \\
& \left.-r(t-1) \frac{E_{p_{k}}(t)-p_{k}(t-1)}{p_{k}(t-1)}\right] \\
& +(1-\tau(t-1)) \frac{p(t-1) Y(t-1)}{p_{k}(t-1) K(t-1)}\left(\frac{E y(t)-y(t-1)}{y(t-1)}\right) . \\
& +\left(E \pi_{k}(t)-\pi_{k}(t-1)\right)
\end{aligned}
$$


where in (3.9) we use the notation (Ey(t)-y(t-1))/y(t-1)

to indicate change in productivity holding factors constant. Now, the right hand side of (3.9) contains the expression $\left[E \pi_{k}(t)-\pi_{k}(t-1)\right]$ which is the expected change in the relative rate of capital gains (relative to the rate of inflation). Thus this is an expectation of the structural relation between the change in prices of finished products relative to capital goods. Being essentially a second order effect, this factor may be ignored. How- . ever, it has been observed that during the 20th century $\pi_{k}(t)=\dot{p}_{k}(t) / p_{k}(t)-\dot{p}(t) / p(t)$ has averaged about .89\% (see, however, Kendrick [1976], p. 27). Thus, given the systematic nature of this variable it is reasonable to assume

$$
E \pi_{k}(t)=\delta \pi_{k}(t-1)
$$

and test the hypothesis $\delta=1$. To add a word of caution we are not certain of the meaning of the data for $p_{k}(t)$ which is the implicit price deflator of the capital stock. The fact that $\pi_{k}(t)$ has a positive rather than 0 mean may suggest that the rise in the price index for $\mathrm{p}_{\mathrm{k}}(\mathrm{t})$ really represents quality or productivity changes and as such should be subtracted from the third term of the expression on the right of (3.9) (i.e., from $\left(E p_{k}(t)-p_{k}(t-1)\right) / p_{k}(t-1)$ ). Also, if the positive mean of $\pi_{k}(t)$ measures quality changes it should really not be viewed as capital gains on the entire stock 
since $p_{k}(t)$ represents the price of the marginal units rather than the price of the stock. We have elected to leave the specification as developed in equation (3.9) since two tests are readily available to us: by (3.9) all the expressions on the right hand of (3.9) must have the same coefficient which we shall denote by $\beta$. This means that the coefficient of $\pi_{k}(t-1)$ is $\beta(\delta-1)$ enabling us to identify $\delta$ and test its difference from 1 . We can now summarize the specification of the basic model. To do that note from (3.2a) that

(3.11) $(I-\tau) \frac{\mathrm{pY}}{\mathrm{p}_{\mathrm{k}}^{\mathrm{K}}}=r+(I-\tau) \frac{\mathrm{wL}}{\mathrm{p}_{\mathrm{k}}^{\mathrm{K}}}$.

Thus using (3.11) we obtain

$$
\begin{aligned}
& (1-\tau(t-1)) \frac{p(t-1) Y(t-1)}{p_{k}(t-1) K(t-1)}\left(\frac{E y(t)-y(t-1)}{y(t-1)}\right) \\
= & r(t-1)\left(\frac{E y(t)-y(t-1)}{y(t-1)}\right)+(1-\tau(t-1)) \frac{W(t-1) L(t-1)}{p_{k}(t-1) K(t-1)}\left(\frac{E y(t)-y(t-1)}{y(t-1)}\right) .
\end{aligned}
$$

Now in order to combine (3.11) and (3.9) define

$$
\begin{aligned}
& X_{1}(t)=(1-\tau(t-1)) \frac{W(t-1) \frac{L}{(t-1)}}{p_{k}(t-1) K(t-1)}\left[\frac{E w(t)-W(t-1)}{w(t-1)}-\frac{E y(t)-y(t-1)}{y(t-1)}\right] \\
& X_{2}(t)=\frac{r(t-1)}{1-\tau(t-1)}(E \tau(t)-\tau(t-1)) \\
& X_{3}(t)=r(t-1)\left[\frac{E p_{k}(t)-p_{k}(t-1)}{p_{k}(t-1)}-\frac{E y(t)-y(t-1)}{y(t-1)}\right]
\end{aligned}
$$

then equation (3.1) combined with (3.6), (3.9) and (3.10) and (3.12) can be written 


$$
\begin{aligned}
\frac{p(t)-p(t-1)}{p(t-1)}= & \alpha\left[r^{*}-r(t-1)\right]-\beta\left[X_{1}(t)+X_{2}(t)+X_{3}(t)\right] \\
& -\beta(1-\delta) \pi_{k}(t-1)
\end{aligned}
$$

We shall in fact estimate an equation like

$$
\begin{aligned}
\frac{p(t)-p(t-1)}{p(t-1)}= & \alpha_{0}-\alpha r(t-1)-\beta_{1} X_{1}(t)-\beta_{2} X_{2}(t) \\
& -\beta_{3} X_{3}(t)-\gamma \pi_{k}(t-1)
\end{aligned}
$$

but restrict $\beta_{1}=\beta_{2}=\beta_{3}$ and test the hypothesis $\delta=1$.

\section{3.b The Effect of Demand and the Concept of "Basic Inflation"}

Our theoretical development in the previous section indicates that small fluctuations in demand will result in fluctuations in output rather than prices. However, this does not contradict the possible traditional effects on the rate of price changes that may be caused by fluctuations in excess demand particularly if such fluctuations are large and unexpected in intensity and duration. Under the pressure of fluctuations in excess demand the atomistic market forces may complement or weaken the complex process of forming correlated pricing strategies. Thus what we are stressing here is the fact that factors of excess demand should be viewed as operating on the rate of inflation independently of the effects of the profit gap. These two factors can either intensify or cancel out each other. Since the empirical analysis which is carried out below covers the period 1909-1974 one 
would expect that some of the intense fluctuations in excess demand were important explanatory factors of inflation during the period of study.

We shall use the unemployment rate $u(t)$ as a proxy measure of the fluctuations in excess demand and add this variable to equation (3.13).

The introduction of demand considerations changes, however, the dynamic structure of equation (3.13). A critical element in the specification is the assumption of no intercept. It then follows that when $r(t-1)=r^{*}, x_{1}(t)=x_{2}(t)=x_{3}(t)=0$ and $\delta=1$ then $p(t)=p(t-I)$. Thus in order to preserve the dynamic interpretation of (3.13) we need to measure not $u(t)$ by itself but the difference between $u(t)$ and $u^{*}$-the normal level of unemployment associated with 0 excess aggregate demand when $r^{*}=r(t-1)$ and $x_{1}(t)=x_{2}(t)=x_{3}(t)=0$. Under the hypothesis $\delta=1$ we can thus rewrite our model with demand effects in the following form:

$$
\begin{aligned}
\frac{p(t)-p(t-I)}{p(t-1)}= & \alpha\left[r^{*}-r(t-I)\right]-B\left[x_{1}(t)+x_{2}(t)+x_{3}(t)\right] \\
& +\gamma\left[u(t)-u^{*}\right]
\end{aligned}
$$

with model (3.15) we can now define the concept of "basic inflation" $b(t)$ to be

$$
b(t)=\alpha\left[r^{*}-r(t-1)\right]+\gamma\left[u(t)-u^{*}\right] .
$$


Since neither the target profit rate-- $r^{*}$ nor the normal, 0 excess demand unemployment rate $-u^{*}$ are observable it is clear that by estimating (3.15) with an unrestricted intercept we shall be estimating the expression

$$
\alpha r^{*}-\gamma u^{*}
$$

and this means that $r^{*}$ and $u^{*}$ are not identifiable. We do have, however, some idea of what a reasonable range for $u^{*}$ can be and in most of the calculations below we shall assume $u^{*}=5 \%$ and then estimate the corresponding value of $r *$

Apart from the identification issue it is the "basic inflation" factor $b(t)$ which plays the crucial role in this research and we need to amplify this point now.

We note first that in the present paper we are not attempting to explain what pushes wages and other cost in response to change in output prices. What is proposed here is that even if there were no expected increase in cost thus $x_{1}(t)=x_{2}(t)=x_{3}(t)=0$ there will still be a residual factor, namely the "basic inflation" $b(t)$, which will continue to exert pressure on prices and in this sense the factors of the profit gap and excess demand are viewed as causing inflation. Obviously, once the inflationary process gets started the feedback between prices and wages and other cost may attain a much greater quantitative weight than the "basic" component of inflation. In order to understand more fully the relative importance of the "basic" and the "feedback" components of inflation the present model will need 
to be expanded and completed. This we expect to do later. In the present paper we shall be able to provide a quantitative measure of the "basic" component.

\section{3.c Other Exogenous Factors}

In addition to the unemployment rate as a proxy to fluctuation in excess demand we shall also test the possible independent effect of the growth rate of real GNP (i.e. $(y(t)-y(t-1) / y(t-1))$ since the rate of unemployment and the growth rate are not perfectly correlated.

The data to be used in this study covers the U.S. economy during the period 1909-1974 and during this period we isolated four episodes which could represent special situations:

(i) $\quad W W I=a$ durmy variable taking the value 1 for the years 1917-1918 measuring the special circumstances of the years of the first World War.

(ii) WW 2 a dummy variable taking the value 1 for the war years 1942-1945 and measuring in fact the effect of price controls during the war.

(iii) $d_{1}=a$ dummy variable taking the value $I$ for the year 1946 to indicate the year in which price controls were removed.

(iv) $\mathrm{d}_{2}=$ a dummy variable taking the value 1 for the year 1951 to measure the effect of the unexpected Korean War. 


\section{3.d Simultaneous Equation Bias}

We view the price determination model as part of a larger system which simultaneously determines the inflation rate, the wage rate $w(t)$, the output leveI $Y(t)$, the tax rate $\tau(t)$, the price of capital goods $p_{k}(t)$ and the unemployment rate $u(t)$. In the estimation procedure to be used, these are always treated as endogenous variables to be replaced by corresponding instrumental variables. The list of exogenous variables used in the estimated first stage equations is given in the Appendix. In equation (3.9) the expected values $E w(t), E \tau(t), E_{k}(t)$ and $E y(t)$ are all estimated with an instrumental variables procedure and are then used in the second stage for the estimation of the price equation.

4. Estimation and Empirical Results

As indicated earlier we estimate our basic model using annual U.S. data for 1909-1974. The three subsections here will present the estimates of the basic model and those of variants allowing for different lag structure and the effect of import prices.

\section{4.a Estimation I: Model (3.15)}

Table 1 presents the result of using 2 stage least squares methods to estimate model (3.15) as discussed above. In choosing the data for $r(t)$ we examined both the post-tax gross and net rates of return on capital, the difference between them being the treatment of depreciation. These two variables are obviously highly correlated and in 
Table 1

2SLS Estimates of Model (3.15)

\begin{tabular}{|c|c|c|c|c|c|c|}
\hline \multirow[b]{2}{*}{ Variables } & \multicolumn{3}{|c|}{ Gross Rate of Return } & \multicolumn{3}{|c|}{ Net Rate of Retum } \\
\hline & 1 & 2 & 3 & 1 & 2 & 3 \\
\hline Constant & $\begin{array}{l}.1342 \\
(.0398)\end{array}$ & $\begin{array}{l}-.1142 \\
(.0409)\end{array}$ & $\begin{array}{l}.1391 \\
(.0279)\end{array}$ & $\begin{array}{l}.0533 \\
(.0263)\end{array}$ & $\begin{array}{l}.0445 \\
(.0269)\end{array}$ & $(.0834)$ \\
\hline$r(t-1)$ & $\begin{array}{l}-1.9070 \\
(.5642)\end{array}$ & 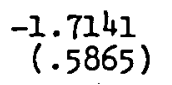 & $\begin{array}{c}-2.0464 \\
(.4297)\end{array}$ & $\begin{array}{l}-.8226 \\
(.3879)\end{array}$ & $\begin{array}{l}-.7873 \\
(.4016)\end{array}$ & $\begin{array}{l}-1.2913 \\
(.3363)\end{array}$ \\
\hline$x_{1}(t)$ & $\begin{array}{l}2.5754 \\
(.7036)\end{array}$ & $\begin{array}{l}4.0053 \\
(.4478)\end{array}$ & $\begin{array}{l}4.0212 \\
(.4462)\end{array}$ & $\begin{array}{l}2.1252 \\
(.5705)\end{array}$ & $\begin{array}{l}3.1281 \\
(.3659)\end{array}$ & $\begin{array}{l}3.1237 \\
(.3775)\end{array}$ \\
\hline$x_{2}(t)$ & $\begin{array}{l}2.5754 \\
(.7036)\end{array}$ & $\begin{array}{l}4.0053 \\
(.4478)\end{array}$ & $\begin{array}{l}4.0212 \\
(.4462)\end{array}$ & $\begin{array}{l}2.1252 \\
(.5705)\end{array}$ & $\begin{array}{l}3.1281 \\
(.3659)\end{array}$ & $\begin{array}{l}3.1237 \\
(.3775)\end{array}$ \\
\hline$x_{3}(t)$ & $\begin{array}{l}2.5754 \\
(.7036)\end{array}$ & $\begin{array}{l}4.0053 \\
(.4478)\end{array}$ & $\begin{array}{l}4.0212 \\
(.4462)\end{array}$ & $\begin{array}{l}2.1252 \\
(.5705)\end{array}$ & $\begin{array}{l}3.1281 \\
(.3659)\end{array}$ & $\begin{array}{l}3.1237 \\
(.3775)\end{array}$ \\
\hline$\pi_{k}(t-1)$ & $\begin{array}{l}.5286 \\
(.2068)\end{array}$ & - & - & $\begin{array}{l}.4690 \\
(.2095)\end{array}$ & - & - \\
\hline$u(t)$ & $\begin{array}{l}-.4585 \\
(.1535)\end{array}$ & $\begin{array}{l}-.3382 \\
(.1533)\end{array}$ & $\begin{array}{l}-.4154 \\
(.1219)\end{array}$ & $\begin{array}{l}-. .3172 \\
(.1593)\end{array}$ & $\begin{array}{c}-.2312 \\
(.1602)\end{array}$ & $\begin{array}{l}-.4249 \\
(.1366)\end{array}$ \\
\hline$\frac{\Delta Y(t)}{Y(t)}$ & $\begin{array}{l}.0484 \\
(.1002)\end{array}$ & $\begin{array}{l}.0868 \\
(.1039)\end{array}$ & - & $\begin{array}{l}.1842 \\
(.0941)\end{array}$ & $\begin{array}{l}.2082 \\
(.0969)\end{array}$ & - \\
\hline WWI & $\begin{array}{l}.1582 \\
(.0308)\end{array}$ & $\begin{array}{l}.1272 \\
(.0297)\end{array}$ & $\begin{array}{l}.1402 \\
(.0252)\end{array}$ & $\begin{array}{l}.1321 \\
(.0281)\end{array}$ & $\begin{array}{l}.1128 \\
(.0277)\end{array}$ & $\begin{array}{l}.1390 \\
(.0257)\end{array}$ \\
\hline WW2 & $\begin{array}{l}.0211 \\
(.0175)\end{array}$ & $\begin{array}{l}.0047 \\
(.0170)\end{array}$ & $\begin{array}{l}.0105 \\
(.0155)\end{array}$ & $\begin{array}{l}.0064 \\
(.0180)\end{array}$ & $\begin{array}{l}-.0087 \\
(.0173)\end{array}$ & $\begin{array}{l}.0051 \\
(.0166)\end{array}$ \\
\hline$\alpha_{1}$ & $\begin{array}{l}.0167 \\
(.0353)\end{array}$ & $\begin{array}{l}-.0086 \\
(.0355)\end{array}$ & $\begin{array}{l}-.0190 \\
(.0332)\end{array}$ & $\begin{array}{l}.0137 \\
(.0370)\end{array}$ & $\begin{array}{c}-.0072 \\
(: 0371)\end{array}$ & $\begin{array}{l}-.0407 \\
(.0347)\end{array}$ \\
\hline$d_{2}$ & $\begin{array}{l}-.0145 \\
(.0280)\end{array}$ & $\begin{array}{l}-.0033 \\
(.0290)\end{array}$ & $\begin{array}{l}-.0016 \\
(.0289)\end{array}$ & $-.0136)$ & $(.0041)$ & $\begin{array}{l}.0009 \\
(.0308)\end{array}$ \\
\hline \multicolumn{7}{|l|}{$\frac{\text { Test of }}{\text { Restrictions }}$} \\
\hline $\begin{array}{l}t \text { value for } \\
B_{1}=B_{2}\end{array}$ & .2983 & .2153 & .6287 & .2570 & .5014 & 1.4688 \\
\hline $\begin{array}{l}t \text { value for } \\
\beta_{2}=B_{3}\end{array}$ & .6810 & .0998 & .4625 & 1.1393 & .0263 & .7608 \\
\hline $\begin{array}{l}F \text { value for } \\
B_{1}=B_{2}=B_{3} \\
\text { against no } \\
\text { restriction }\end{array}$ & .3860 & .0441 & .2184 & .2108 & .5735 & .1731 \\
\hline \multicolumn{7}{|c|}{$\frac{\text { Estimated Model }}{\left.\text { Parameters (under } u^{*}=.05\right)}$} \\
\hline $\mathrm{r}^{*}$ & .058 & .057 & .058 & .046 & .042 & .048 \\
\hline$\hat{a}$ & 1.9070 & 1.7141 & 2.0464 & .8226 & .7873 & 1.2913 \\
\hline$\hat{B}$ & 2.5754 & 4.0053 & 4.0212 & 2.1252 & 3.1281 & 3.1237 \\
\hline$\hat{\delta}$ & .7948 & - & - & .7793 & - & - \\
\hline $\begin{array}{l}\text { Mean Square } \\
\text { Error }\end{array}$ & .00072 & .00080 & .00079 & .00079 & .00085 & .00091 \\
\hline
\end{tabular}


principle it should matter little which one we select. However, since the depreciation rate is really an endogenous policy variable, the net rate of return is influenced by the way accounting methods of depreciation change over time and the tax treatment of these changes. This means that the reported net rate of return may provide an inaccurate picture of the true profitability of the firm. The example of accelerated depreciation provides a particularly sharp demonstration how inappropriate is the net rate to our purpose. Here accelerated depreciation increases the true profitability of the firm due to reduced taxes but it decreases the reported after-tax net rate of return on capital. Due to these considerations we accept in this work the gross rate as a basis for analysis and all the discussion in later sections is based on the results of the "gross" equations. We present the estimates for the "net" equations in Table 1 only. Note that as far as the goodness of fit is concerned the gross rate of return provides a better statistical fit to models (3.15) and (4.3) below.

We must first dispose of the question of testing the hypothesis $\delta=1$. The estimated value of $\delta$ is .7948 in the "gross" equation and .7793 in the "net" equation. Recall from (3.13) that if we denote the coefficient of $\pi_{k}(t-1)$ by $\gamma$ then the true relation is

$$
(1-\delta)=\frac{\gamma}{\beta}
$$

By Rao's theorem (see Dhrymes [1974], Proposition 6, pages 112-113) the random variable $(1-\hat{\delta})$ has an asymptotic normal distribution with a variance given by the expression 


$$
\left(\begin{array}{c}
\frac{I}{\hat{\beta}} \\
\hat{\underline{\gamma}}
\end{array}\right)^{\prime}\left(\begin{array}{c}
\frac{I}{\hat{\beta}} \\
\hat{\hat{\beta}}
\end{array}\right)
$$

where $\hat{\Sigma}$ is the estimated variance covariance matrix of the vector $(\hat{\gamma}, \hat{\beta})$. Calculating the standard deviation of $(1-\hat{\delta})$, we find that it is . 1294 for the "gross" model (thus the $t$ value is 1.5859 ) and .1496 for the "net" case (resulting in a $t$ value of 1.4744 ). In either one of the two cases $\hat{\delta}$ is not significantly different from $I$. This leads us to accept the hypothesis $\delta=1$ and proceed in the rest of this paper to analyze the model under this restriction. The conclusion to ignore the variable $\pi_{k}(t-1)$ is reinforced by our earlier doubts about its interpretation.

Before proceeding to the analysis of our basic model note the two variables $u(t)$ and $\Delta Y(t) / Y(t)$. These variables represent the fluctuations in demand and these are clearly important. The unemployment variable has a negative coefficient which is statistically significant while the growth rate of real output is positive and not significant. I/ Furthermore, since $\Delta Y(t) / Y(t)$ is correlated with $u(t)$ the removal of $\Delta Y(t) / Y(t)$ increases the coefficient of $u(t)$ and reduces the standard errors of other variables. We thus conclude that the effect of variations in demand on the rate of inflation is statistically significant and will be represented by the unemployment variable only. We thus restrict our discussion to equations type 3 in Table 1 . 
Turning now to the evaluation of the model parameters we note that in the "gross" equation 3, $r^{*}=.068, \hat{\alpha}=2.0464$ and $\beta=4.0212$. Since the mean value of the gross rate of return $r(t)$ is .0544 the difference between the target $r^{*}$ and .0544 is of great interest and we return to this question later. On the other hand, the basic restrictions proposed by the model i.e. $\beta_{1}=\beta_{2}=\beta_{3}=\beta$ are justified by the passage of their significance tests.

The crucial variable of our model is $r(t-1)$ and as suggested earlier the essential test of our model is represented by the sign and size of its coefficient. We find that $\hat{\alpha}=2.0464$ representing a major trade-off between the rate of inflation and the rate of profits: for each 1 percentage point variation in the gross profit rate this model suggests an induced change of 2 percentage points in the inflation rate. Interestingly enough the value of $\beta$ is estimated to be around 4, indicating an extremely rapid rate of price reaction to current changes in the profit rate due to cost. This major difference between $\alpha$ and $\beta$ is interesting and we shall return to it below after reviewing all the emprical results. The net effect of fluctuations in demand is interesting. The unemployment rate has a significant net negative effect on the rate of inflation and the estimate of -.4154 is important. It suggests that in order to reduce the inflation rate by I percentage point the unemployment rate will need to rise by 2.4 percentage points! This is a much more extreme trade-off than is familiar from the Phillips curve literature.

Finally the dummy variables describing the "special" episodes contribute little except for the first world war. We find this to be 
an encouraging result suggesting that the variations in the rate of inflation are well explained by the other variables of the model.

\section{4.b Estimation II: The Indirect Effect of Import Cost}

Our theory of endogenous inflation rate relates to the prices of all domestically produced commodities over which producers have control. The variable which measures this rate of inflation is. the GNP deflator which measures the price index of domestic value added. Because of this we used the GNP price deflator for $p(t)$ and the GNP itself for $Y(t)$. It is crucial to note that the GNP deflator is totally unresponsive to the direct changes in import prices. To see this note that nominal GNP is the sum of consumption, investment, government expenditures and exports minus imports. If the price of imports rises while all quantities do not change then both the nominal as well as the real GNP do not change explaining why the deflator is not directly sensitive to the changes in the price of imports.

The critical observation which should be made is that changes in the prices of imports could influence the prices of domestic value added only via their effects on profitability. Thus, if we think of all imports as if they were producer goods used in the production of domestic commodities, then we can define "output" by the expression

$$
\tilde{\mathrm{p}} \tilde{\mathrm{Y}}=\text { consumption }+ \text { investment }+ \text { government expenditures + exports }
$$

and think of $\tilde{p}$ as the price deflator of this quantity. On this basis we have the identity 


$$
\tilde{p}(t) \tilde{Y}(t)-\text { Imports }=p(t) Y(t)
$$

and therefore

(4.2) $\quad r(t)=\frac{\tilde{p}(t) \tilde{Y}(t)-w(t) L(t)-p_{I m}(t) I_{m}(t)}{p_{k}(t) K(t)}(1-\tau(t))$

where

$$
\begin{aligned}
p_{I m}(t)= & \text { price of import goods } \\
I_{m}(t)= & \text { volume of imports } \\
\tilde{p}(t)= & \text { the price deflator of the aggregate value of consumption, } \\
& \text { investment, government expenditures and exports. }
\end{aligned}
$$

Since $\tilde{\mathrm{p}}$ is a domestic price which is controlled by domestic producers we think of it as an endogenous variable and do not assume that any change in the price of imports should necessarily induce a corresponding change in $\tilde{p}$. We can thus conclude that a rise in $p_{I m}(t)$-the price of imports--without changing domestic prices will not change the GNP or the price deflator but it will reduce total profits! This suggests that our theory of domestic inflation should consider the effect of changes in the price of imports not in terms of the direct effect of import prices on commodity prices in the domestic markets, but rather in terms of the indirect effect of such price changes on domestic profitability. To accomplish this we need to redefine model (3.13) with the aid of definition (4.2). To do this, define 


$$
\begin{aligned}
& x_{1}(t)=(1-\tau(t-1)) \frac{w(t-1) L(t-1)}{p_{k}(t-1) K(t-1)}\left[\frac{E w(t)-w(t-1)}{w(t-1)}-\frac{E y(t)-y(t-1)}{y(t-1)}\right] \\
& x_{2}(t)=\frac{r(t-1)}{1-\tau(t-1)}(E \tau(t)-\tau(t-1)) \\
& x_{3}(t)=r(t-1)\left[\frac{E p_{k}(t)-p_{k}(t-1)}{p_{k}(t-1)}-\frac{E y(t)-y(t-1)}{y(t-1)}\right] \\
& x_{4}(t)=(1-\tau(t-1)) \frac{p_{I m}(t-1) I_{m}(t-1)}{p_{k}(t-I) K(t-I)}\left[\frac{E_{I m}(t)-p_{I m}(t-1)}{p_{I m}(t-1)}-\frac{E y(t)-y(t-I)}{y(t-1)}\right]
\end{aligned}
$$

and with these definitions we can rewrite the price adjustment model as follows :

$$
\begin{aligned}
\frac{p(t)-p(t-1)}{p(t-1)}= & \alpha\left[r^{*}-r(t-1)\right]+\beta\left[x_{1}(t)+x_{2}(t)+x_{3}(t)+x_{4}(t)\right] \\
& +\gamma\left[u(t)-u^{*}\right]+\gamma_{1} w w_{1}+\gamma_{2} w w 2+\gamma_{3} d_{1}+\gamma_{4} a_{2} .
\end{aligned}
$$

Table 2 presents the results of estimating equation (4.3). A comparison of Tables 1 and 2 indicates that the estimates of $r^{*}, \alpha$ and $\beta$ are basically the same except that the mean square error in Table 2 is some $35 \%$ lower than in Table 1 and the standard errors of the coefficients are much lower. Thus the estimates of model (4.3) suggests an improvement in efficiency over model (3.13). It is also encouraging that the basic test of the restrictions $\beta_{1}=\beta_{2}=\beta_{3}=\beta_{4}=\beta$ leads to accepting all of them. We have separately tested the null hypothesis $\beta_{1}=\beta_{2}=\beta$ while $\beta_{3}$ and $\beta_{4}$ unrestricted. We find that the $F$ test of the hypothesis $\beta_{1}=\beta_{2}=\beta_{3}=\beta_{4}$ against no restrictions leads to the acceptance of the equality of all the $\beta_{j}$. 


\section{Table 2}

2SLS Estimates of Model. (4.3) with Import Variable

Gross Rate of Return

\section{Variables}

Constant

.1416

(.0225)

$r(t-1)$

$-2.0345$

$x_{1}(t)$

$(.3468)$

$x_{2}(t)$

3.7347

$(.3205)$

$x_{3}(t)$

3.7347

$(.3205)$

$x_{4}(t)$

3.7347

$(.3205)$

$u(t)$

3.7347

(.3205)

us

$-.4467$

(.0975)

WWI

.1424

$(.0205)$

WW2

.0105

(.0126)

$\mathrm{d}_{1}$

$-.0115$

$(.0266)$

$d_{2}$

$-.0059$

$(.0236)$

Test of Restrictions

$t$ value for $\beta_{1}=\beta_{2}$

.2764

$t$ value for $\beta_{2}=\beta_{3}$

.1348

$t$ value for $\beta_{3}=\beta_{4}$

.4832

$F$ value for $\beta_{1}=\beta_{2}=\beta_{3}=\beta_{4}$

.1031

against no restrictions

\section{Estimated Model Parameters}

$\mathrm{r}^{*}$
$\hat{\alpha}$
$\hat{\beta}$

.059

2.0345

3.7347

Mean Square Error .00053 
4.c Estirnation III: The Lag Structure and Serial Correlation The "profit gap" in equation (3.11) is defined by $[r * r(t-1)]$. If firms take longer than 1 period to establish what the profit rate is we may replace $r(t-1)$ by an expression $r_{c}(t-1)$ defined by

$$
r_{c}(t-1)=\sum_{j=1}^{J} \gamma_{j} r(t-1-j)
$$

The need for a longer lag structure may also arise from the time it takes to establish a correlated price strategy. However the results in Table 3 which give the estimates for $J=2$ suggest that a longer lag is not needed.

We have also tested a Koyck type distributed lag in which $\gamma_{j}=\lambda^{j}$, $0<\lambda<1$. The results were inconsistent and unsatisfactory convincing us to reject the possibility of $J=+\infty$.

The fact that the profit-lag is short suggests that firms establish their pricing strategies rather quickly. This conclusion is particularly interesting in view of the long duration of an inflationary process. The conclusion of short rather than long profit lags raises the possibility of no lag at all suggesting to define the profit gap by the expression $\left[r^{*}-r(t)\right]$. We have rejected this formulation as inappropriate for our theory and the reason is now given. In order to think of the profit gap as causing a formation of a price adjusting correlated strategy there must be a time lag between the observations made on the profit rate and the actual price adjustment. 
Table 3

2SLS EStimates of Model (4.3) with Longer Lag Structure Gross Rate of Return

Variables

Constant

$i$

$r(t-1)$

$r(t-2)$

$x_{1}(t)$

$x_{2}(t)$

$x_{3}(t)$

$x_{4}(t)$

$u(t)$

WWI

WW2

$d$

$\mathrm{d}_{2}$

Test of Restrictions

$t$ value for $\beta_{1}=\beta_{2}$

$t$ value for $\beta_{2}=\beta_{3}$

$t$ value for $\beta_{3}=\beta_{4}$

$F$ value for $\beta_{1}=\beta_{2}=\beta_{3}=\beta_{4}$ against no restrictions

Estimated Model Parameters

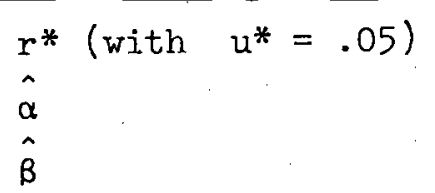

Mean Square Error
2 Lag Model

.1401

(.0230)

$-1.6024$

(.6230)

$-.4133$

$(.4727)$

3.7585

(.3294)

3.7585

$(.3294)$

3.7585

$(.3294)$

3.7585

$(.3294)$

$-.4306$

(.1033)

.1333

(.0238)

.0067

(.0135)

$-.0110$

(.0239)

$-.0053$

$(.0239)$

.0077

.0546

.1740

.0272

.059

2.0157

3.7585

.00054 
This time lag measures the rate at which information flows among firms and decisions are made. Given the fact that it takes firms a significant amount of time to discover their own profit rate and even Ionger to establish the profit rates of their competitors it is clear that some time lag must be allowed and in the context of our theory the profit rate of a firm and its price adjustment strategy cannot possibly be assumed to be simultaneously determined. What may cause a problem is the annual structure of our data and the possibility that the time lag is less than one year. If one goes to the other extreme and assumes no time lag, then, holding all other variables constant, the definition of $r(t)$ in (3.2a) or (4.2) establishes in the annual data used here an accounting identity between $r(t)$ and $p(t)$. With this, no causal relationship between them would make any sense. Inspite of our own reasons to reject the no lag model the interested reader may find in Table 4 the results for the simultaneous equations estimates of model (4.3) with no lag. However, the main objective of Table 4 is to present the results of reestimating model (4.3) with a correction for serial correlation. The procedure adopted here is based on Fair [1970] (Section 3).

As Table 4 shows, the results for the one year lag model with full correction for serial correlation are very similar to the results in Table 2. 
Table 4

2\$IS Estimates for Model (4.3) with Import Variable Gross Rate of Return, Correction for Serial Correlation

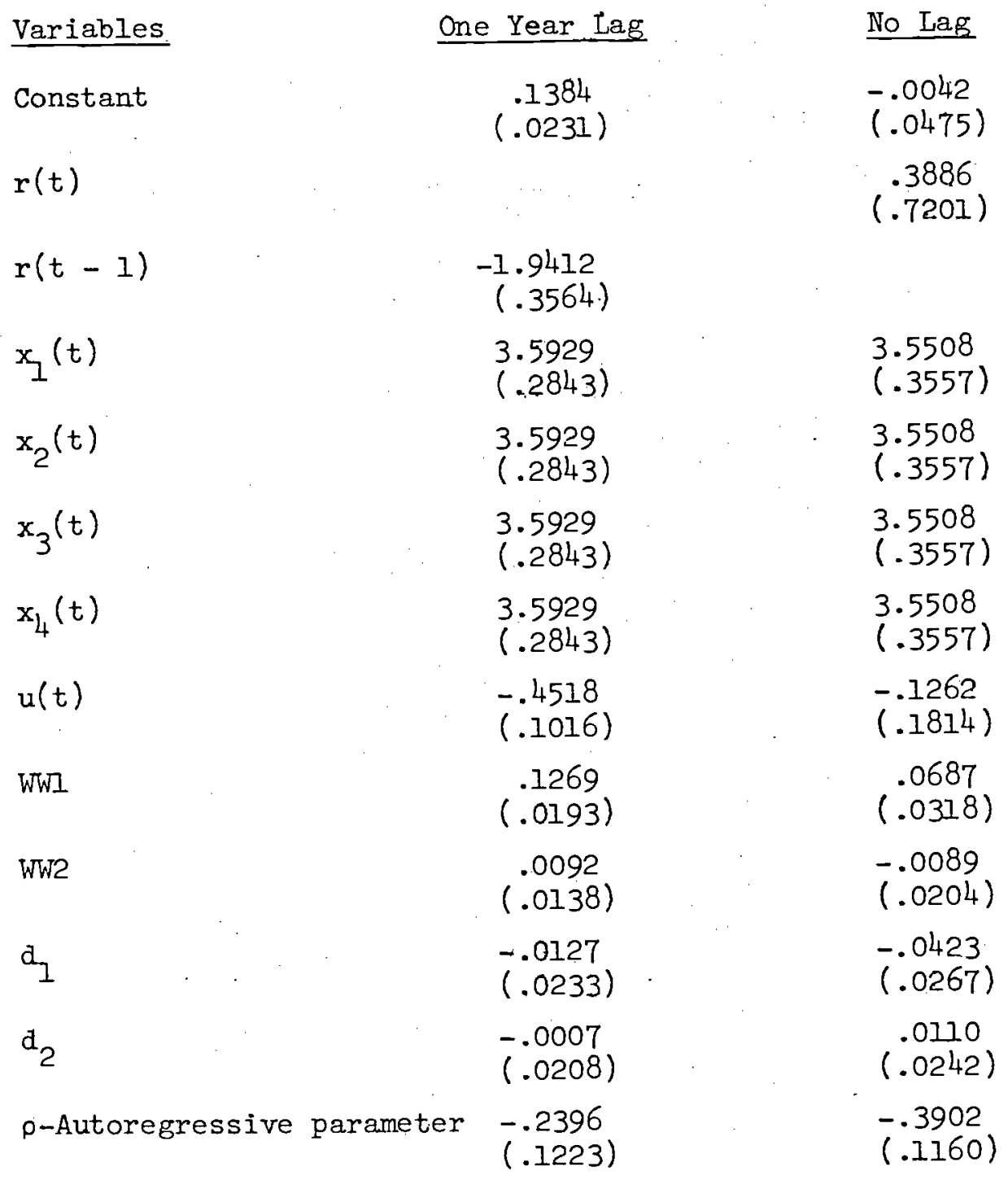

Estimated Model Parameters

$\begin{array}{ccc}\left.\mathrm{r}^{*} \text { (with } \mathrm{u}^{*}=.05\right) & .060 & .027 \\ \hat{\alpha} & 1.9412 & -.3886 \\ \hat{\beta} & 3.5929 & 3.5508 \\ \text { Mean Square Error } & .000442 & .000658\end{array}$


5. Implications of the Empirical Results

This section will draw a few of the immediate implications of our results. Deeper analysis relating to a general equilibrium model of the U.S. economy will be postponed to another paper.

5.a The Trade-Off between Inflation and Profitability

The stochastic form of (4.3) can be written in the following way:

$$
\begin{aligned}
\frac{p(t)-p(t-1)}{p(t-1)}= & \alpha\left[r^{*}-r(t-1)\right]+\beta[E p(R(t))-R(t-1)]+\gamma\left[u(t)-u^{*}\right] \\
& +\gamma_{1} w w 1+\gamma_{2} w w 2+\gamma_{3} d_{1}+\gamma_{4} d_{2}+\varepsilon(t)
\end{aligned}
$$

In order to isolate the effect of the "profit gap" $\left[r^{*}-r(t-I)\right]$ in relation to $\varepsilon(t)$ we can define the "adjusted rate of inflation" as

$$
\text { (5.2) } \begin{aligned}
\psi(t)= & \frac{p(t)-p(t-1)}{p(t-1)}-\beta[\operatorname{Ep}(R(t))-R(t-1)]-\gamma\left[u(t)-u^{*}\right]-\gamma_{1} w w 1 \\
& -\gamma_{2} w w 2-\gamma_{3} d_{1}-\gamma_{4} d_{2} \\
= & \alpha\left[r^{*}-r(t-1)\right]+\varepsilon(t) .
\end{aligned}
$$

Thus $\psi(t)$ is the inflation rate corrected for all the variables except for the profit gap. Now given the estimates of $\hat{r}^{*}, \hat{\alpha}, \hat{\beta}, \hat{\gamma}, \hat{\gamma}_{1}, \hat{\gamma}_{2}, \hat{\gamma}_{3}$ and $\hat{r}_{4}$ we calculate $\hat{\psi}(t)$--the estimated value of $\psi(t)$ and plot it against $r(t-1)$. Using the equation (4.3) with imports, Diagram 4 presents the scatter for the gross rate of return equation. The scales of $\hat{\psi}(t)$ and $r(t-1)$ are the same so that the slope of the scatter is the actual slope measured by $\hat{\alpha}$. One notes that the negative slope is distinct and even the extreme points fit the slope well. 
$-48-$

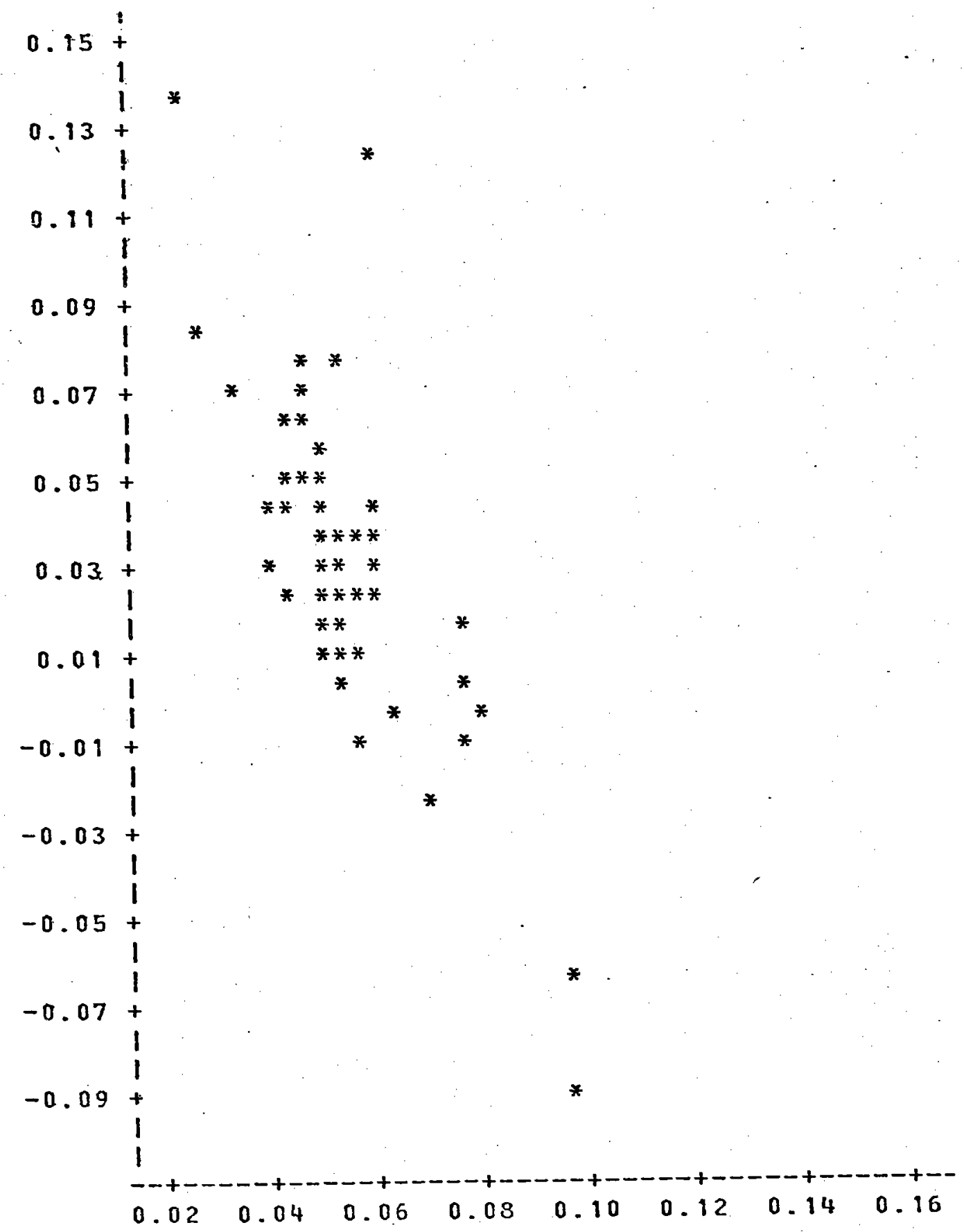

Diagram 4

Gross Rate of Return 
Clearly every percentage point change in the profit gap causes a 2.0345 percentage point change in the inflation rate which is measured by the GNP deflator. This is a large effect and a major trade of $f$ indeed.

\section{5.b The Rate of Basic Inflation}

Let us disregard, for the moment, the variables wwl, ww2, dl and d2 and write the estimated model in the following way:

$$
\text { (5.1) } \frac{p(t)}{p(t)}=2.0345\left[r^{*}-r(t-1)\right]+3.7347[E p(R(t))-R(t-1)]-.4467\left[u(t)-u^{*}\right] \text {. }
$$

Then one can see that the implied relationship between $r^{*}$ and $u^{*}$ is illustrated in the following table:

$\begin{array}{ll}\underline{u^{*}} & \underline{r^{*}} \\ 0.00 & .0690 \\ .01 & .0668 \\ .02 & .0646 \\ .03 & .0624 \\ .04 & .0602 \\ .05 & .0580 \\ .06 & .0558\end{array}$

keep in mind that $\mathrm{u}^{*}$ is important to our model only to the extent that it is a proxy for the condition of no excess demands. If we could observe excess demands directly, we would have estimated the model with this variable and would have derived the target profit rate from it as proposed above in (5.1). 
The key explanatory variable in our theory is the "basic inflation" rate defined in (3.16) and is estimated to be

$$
b(t)=.1416-2.0345 r(t-1)-.4467 u(t) \text {. }
$$

In practice it is this variable which is the focus of this research since it measures the basic inflationary pressures which are present even without the feedback of the cost-price spiral. To understand this point note again that in this paper we are not attempting to explain what pushes up wages and other cost. What we have established is that even if we take the cost increases as given, there are basic inflationary forces at work even if costs do not rise. Since the "basic inflation" measures these forces it has the character of being a cause for inflation. To indicate the relative importance of the "basic inflation" as an explanatory factor of total inflation let us calculate it for recent years:

$\begin{array}{lcccc}\text { Year } & \frac{\text { Inflation }}{\text { Rate }} & \frac{\text { Basic }}{\text { Inflation }} & \frac{\text { Basic Inflation as a }}{\text { Fraction of Total }} \\ 1967 & 2.9 \% & -.2 \% & -6 \% \\ 1968 & 4.5 & .7 & 16 \\ 1969 & 5.0 & 1.6 & 32 \\ 1970 & 5.4 & 2.0 & 37 \\ 1971 & 5.1 & 2.1 & 42 \\ 1972 & 4.1 & 1.7 & 41 \\ 1973 & 5.9 & 2.0 & 34 \\ 1974 & 9.7 & 1.5 & 15\end{array}$




\section{5.c The Adjustment Rates}

Since both $\left[r^{*}-r(t-1)\right]$ and $\left[E_{p}(R(t))-R(t-I)\right]$ measure profitability gaps (in percentages) one would expect $\alpha$ and $\beta$ to be similar in magnitude. It is an interesting fact that our estimate of $\alpha$ is about 2 while the estimate for $\beta$ is about 3.7. This result means that a change in the profit rate due to changes in current cost induces a response which is almost twice as fast as the response to an accumulation of factors (some random) which resulted in inequality between $r^{*}$ and $r(t-1)$. Putting this same thing differently there is a significant difference between adjusting prices in response to changes in cost which provide an observed signal to all, and adjusting prices in response to an accumulation of factors which create a profitability gap. In view of the delicate process of forming a pricing strategy this result is not totally surprising.

The basic explanation to the phenomenon at hand is related to the way information is passed among the participants in the market and to the way it is being perceived. Rising cost is a very simple and uniform signal which is clearly seen and understood by all and would thus generate a uniform response regardless whether $r^{*}>r(t)$ or $r^{*}<r(t)$. On the other hand the existence of a profit gap will induce a more subtle and complex process and there are three main reasons why the estimated $\hat{\alpha}$ may be smaller than $\hat{\beta}$ :

(i) it takes time for information to pass and to have all the participants agree to adhere to a price adjustment strategy. 
During such a transition period there will be no observed response to a profitability gap

since the process involves some uncertainties, even after the adoption of a price adjustment strategy the tendency would be to move slowly and to check that all are following the strategy. If prices are raised too fast some participants may be reluctant to follow due to the risk involved

(iii) the estimated coefficient $\hat{\alpha}$ represents average responses when $r^{*}>r(t)$ and $r^{*}<r(t)$. It is possible that when $r(t)>r^{*}$ the response tends to be slower than when $r^{*}>r(t)$ in which case the mean can be smaller than $\beta$.

\section{5.d Classification of Inflations}

Although ve have made little use of the distinction between costpush and demand-pull inflations we do think that periods of rapid price changes can be classified into different categories. However, in using our model for that purpose we have a slight terminological problem since both the profit gap $\left[r^{*}-r(t-1)\right]$ and the expected gap $\left[F_{p}(R(t))-\right.$ $R(t-1)]$ are influenced by cost. For this reason we shall not use the terminology of "cost-push" inflation.

We suggest that an interesting classification of inflations can be made by comparing the contribution of demand, measured by the rate of unemployment, with the contributions of the profit gap $\left[r^{*}-r(t-1)\right]$ to the inflation rate. If an inflation or a deflation is dominated by demand we say that it is "demand induced" and if it is dominated by the profit gap we say that it is "profitability induced." 
To do this define

$$
\begin{array}{ll}
\Phi_{p}(t)=2.0345\left[r^{*}-r(t-1)\right] & \text { with } r^{*}=.0579 \\
\Phi_{d}(t)=.4467\left[u^{*}-u(t)\right] & \text { with } u^{*}=.05
\end{array}
$$

Here $\Phi_{p}(t)$ measures the inflationary pressures due to profitability and $\Phi_{d}(t)$ measures the pressures due to demand. On this basis we suggest the following classification:

(i) Demand Induced Inflation: if $\Phi_{d}(t)>\Phi_{p}(t), \Phi_{d}(t)>0$ and $\dot{p}(t) / p(t)>0$

(ii) Demand Induced Deflation: if $\Phi_{d}(t)<\Phi_{p}(t), \Phi_{d}(t)<0$ and $\dot{p}(t) / p(t)<0$

(iii) Profitability Induced Inflation: if $\Phi_{p}(t)>\Phi_{d}(t), \Phi_{p}(t)>0$ and $\dot{p}(t) / p(t)>0$

(iv) Profitability Induced Deflation: if $\Phi_{p}(t)<\Phi_{d}(t), \Phi_{p}(t)<0$ and $\dot{p}(t) / p(t)<0$.

If an inflationary period does not satisfy any of the above we shall call it "ambiguous." On the other hand if $\Phi_{d}(t)$ and $\Phi_{p}(t)$ have the same sign but are within .5 of each other we shall classify such a period as "both" because the classification depends upon the selection of the unemployment rate $u^{*}$ and we certainly regard the selection of $u^{*}=.05$ as arbitrary.

In the analysis below we consider all years during 1909-1974 in which $\dot{p}(t) / p(t)$ exceeded $3 \%$ in absolute value. The tables record the values of $\Phi_{p}(t), \Phi_{d}(t)$ and the implied classification. 
Period 1: 1909-1929

$\begin{array}{lcccc}\text { Year } & \dot{p}(t) / p(t) & \Phi_{d}(t) & \Phi_{p}(t) & \text { Classification of Price Changes } \\ 1912 & 3.9 \% & +.18 & +.85 & \text { Profitability induced } \\ 1915 & 3.2 & -1.58 & +2.22 & \text { Profitability induced } \\ 1916 & 12.8 & -.05 & -.37 & \text { Ambiguous } \\ 1917 & 23.2 & +18 & -3.72 & \text { Demand induced } \\ 1918 & 16.5 & +1.62 & -8.09 & \text { Demand induced } \\ 1919 & 2.5 & +1.62 & -8.16 & \text { Demand induced } \\ 1920 & 13.9 & -.09 & -4.01 & \text { Ambiguous } \\ 1921 & -14.8 & -3.02 & -.31 & \text { Demand induced } \\ 1922 & -5.5 & -.77 & +1.75 & \text { Demand induced } \\ 1923 & 2.8 & +1.17 & +2.34 & \text { Profitability induced }\end{array}$

Period 2: $1929-1940$

$\begin{array}{lcccl}\text { Year } & \dot{p}(t) / p(t) & \Phi_{d}(t) & \Phi_{p}(t-1) & \text { Classification of Price Changes } \\ 1930 & -2.6 \% & -1.67 & -.59 & \text { Demand induced } \\ 1931 & -9.1 & -4.64 & 1.08 & \text { Demand induced } \\ 1932 & -10.3 & -7.88 & 2.95 & \text { Demand induced } \\ 1933 & -2.2 & -7.02 & 6.27 & \text { Demand induced } \\ 1934 & 7.4 & -4.95 & 6.78 & \text { Profitability induced } \\ 1935 & .9 & -4.14 & 5.21 & \text { Profitability induced } \\ 1936 & .2 & -2.21 & 3.97 & \text { Profitability induced } \\ 1937 & 4.2 & -1.85 & 3.07 & \text { Profitability induced } \\ 1938 & -.1 & -3.38 & 3.01 & \text { Demand induced }\end{array}$


This period is interesting in the fact that during 1930-1938 demand forces appear to exert pressures on price declines while profitability was exerting pressures on prices to rise. The outcome appears to be divided: the early period (1930-1933) exhibits the domination of demand factors while the later period shows the domination of profitability factors. This period provides unusual demonstration of the key element of our theory: inspite of a $16 \%$ unemployment rate in 1934 inflation was proceeding at an annual rate of $7.4 \%$ (!) and the low profitability of that era is the important factor in explaining it.

\section{Period 3: $\quad 1941-1967$}

During this period the effects of price controls during the war and the effects of removing the controls in 1946-47--all cause a slight distortion; the high inflation rate in $1946-47$ is a bit abnormal and is mostly explained by the rapid rise in wages immediately after the war

\begin{tabular}{lcccl} 
Year & $\mathrm{p}(\mathrm{t}) / \mathrm{p}(\mathrm{t})$ & $\Phi_{\mathrm{d}}(\mathrm{t})$ & $\Phi_{\mathrm{p}}(\mathrm{t})$ & \multicolumn{1}{l}{ Classification of Price Changes } \\
1941 & $7.5 \%$ & -.45 & +2.40 & Profitability induced \\
1942 & 12.3 & +.86 & 1.95 & Profitability induced \\
1943 & 7.0 & +1.44 & -.39 & Demand induced \\
1944 & 2.6 & +1.71 & -2.44 & Demand induced \\
1945 & 2.6 & +1.40 & -4.52 & Demand induced \\
1946 & 11.7 & +.50 & -3.50 & Demand induced \\
1947 & 12.8 & +.50 & +1.20 & Profitability induced \\
1948 & 6.9 & +.54 & +1.79 & Profitability induced \\
1951 & 6.8 & +.77 & +1.24 & Both \\
1956 & 3.1 & +.41 & +.77 & Both \\
1957 & 3.4 & +.32 & -.43 & Demand induced
\end{tabular}


Period 4: $1968-1974$

\begin{tabular}{lcccl} 
Year & $\dot{p}(t) / p(t)$ & $\Phi_{\mathrm{d}}(t)$ & $\Phi_{\mathrm{p}}(t)$ & \multicolumn{2}{l}{ Classification of Price Changes } \\
1958 & $4.5 \%$ & +.63 & +.08 & Demand induced \\
1969 & 5.0 & +.68 & +.85 & Both \\
1970 & 5.4 & +.05 & +1.79 & Profitability induced \\
1971 & 5.1 & -.41 & +2.34 & Profitability induced \\
1972 & 4.1 & -.27 & +1.89 & Profitability induced \\
1973 & 5.9 & +.05 & +1.73 & Profitability induced \\
1974 & 9.7 & -.27 & +1.69 & Profitability induced
\end{tabular}

The most distinct feature of the $1966-1974$ period is the sharp decline of the profit rate from the peak of $6.2 \%$ in 1966 to $4.5 \%$ in 1974 . Our model suggests that by 1970 the rate of price increase switched from being demand induced to being profitability induced.

\subsection{The Anatomy of Inflation 1971-1977}

We now use model (4.3) to predict the inflation rates for the period 1975-1977. Since we do not have updated information for all the independent variables used in the first stage, we shall use in the predictions below the actual values of the variables on the right hand side of (4.3). In order to aid the comparability of the results we also present the corresponding values for the period 1971-1974 the data for which was used in the estimation.

Table 5 presents the results. One may note that apart from 1974-1975 the prediction error is not large. The negative error in 1974 resulted from the fact that the model responded to the large cost increases in 1974 faster than the economy. Thus it took the 
Table 5

Analysis of Inflation 1971-1977

\begin{tabular}{|c|c|c|c|c|c|c|c|}
\hline & 1971 & 1972 & 1973 & 1974 & 1975 & 1976 & $1977^{\circ}$ \\
\hline $\begin{array}{c}\text { Actual } \\
\text { Inflation Rate }\end{array}$ & $5.10 \%$ & $4.14 \%$ & $5.80 \%$ & $9.69 \%$ & $9.62 \%$ & $5.27 \%$ & $5.56 \%$ \\
\hline $\begin{array}{c}\text { Predicted } \\
\text { Inflation Rate }\end{array}$ & 4.46 & 5.02 & 5.86 & 11.68 & 7.10 & 4.52 & 5.63 \\
\hline $\begin{array}{l}\text { Decomposition } \\
\text { of Prediction }\end{array}$ & & & & & & & \\
\hline Due to the Profit Gap & $2.47 \%$ & $2.04 \%$ & $1.87 \%$ & $1.92 \%$ & $2.61 \%$ & $2.05 \%$ & $1.91 \%$ \\
\hline Due to demand & -.40 & -.27 & -.05 & -.27 & -1.56 & -1.21 & -.89 \\
\hline $\begin{array}{l}\text { Expected Increased } \\
\text { Gap due to Domestic } \\
\text { Cost }\end{array}$ & 2.32 & 3.10 & 3.29 & 7.76 & 5.68 & 3.71 & 4.27 \\
\hline $\begin{array}{l}\text { Expected Increase Gap } \\
\text { due to Import Cost }\end{array}$ & .06 & .14 & .65 & 2.27 & .37 & -.04 & .34 \\
\hline $\begin{aligned} \text { Error }= & \text { Actual } \\
& - \text { Predicted }\end{aligned}$ & .64 & -.88 & -.06 & -1.72 & 2.52 & .75 & -.07 \\
\hline
\end{tabular}

economy an extra year to absorb the extra-ordinarily high rate of $10.7 \%$ wage increase and $50.4 \%$ increase in the unit price of imports. Due to this temporary adjustment period the model prediction is above the actual rate in 1974 and below the actual rate in 1975.

The analysis shows that the profit gap has accounted consistently for some 2-2.5 percentage points of the inflation rate during this period. The effect of demand has been more volatile and so has been the cost components. It is perhaps worth indicating that the $2.27 \%$ contributions 
of imports in 1974 should be understood to mean that the rise of import cost, in causing a potential decline in the profit rate has induced a price increase in the domestic value added of GNP due simply to the substitutability between imported and domestic commodities. This should not be confused with the direct increase in the price level due to the direct increase in the imported component of the price index resulting from the rise of import prices. Such a component does not exist in the GNP deflator and is excluded from analysis here.

Using our earlier classification, the inflation of 1971-1977 would certainly be viewed as profitability induced. Clearly the component which we called "basic inflation" has contributed significantly during this period as the following shows:

$\begin{array}{lcc}\text { Year } & \text { Basic Inflation } & \begin{array}{c}\text { Basic Inflation as } \\ \text { a Fraction of the Total }\end{array} \\ 1971 & 2.07 \% & 41 \% \\ 1972 & 1.77 & 43 \\ 1973 & 1.82 & 32 \\ 1974 & 1.65 & 17 \\ 1975 & 1.05 & 11 \\ 1976 & .84 & 16 \\ 1977 & 1.02 & 18\end{array}$

What is interesting here is that the fraction of basic inflation in the total falls from 1971 to 1975 and then rises again. This is partly caused by the recorded unemployment rate which has undergone structural changes due to the labor supply of women and teen-agers. This factor 
really causes a distortion of the explanatory power of unemployment to inflation. However the observed pattern may also suggest that once the inflationary process starts it tends to become dominated by the feedback component. We note that by 1975 the basic inflation component has declined to $11 \%$ of the total and one might suggest that the rise of this component after 1975 would represent a resurgence of inflationary forces beyond 1977 .

Clearly these are only conjectures which need much further study and whose investigation will require a general equilibrium setting. We expect to complete this work later on.

Finally let us consider the evolution, in the 1970 's, of the profit and unemployment rates:

$\begin{array}{lcc} & \text { Profit Rate } & \text { Unemployment Rate } \\ 1971 & 4.86 \% & 5.9 \% \\ 1972 & 4.94 & 5.6 \\ 1973 & 4.92 & 4.9 \\ 1974 & 4.58 & 5.6 \\ 1975 & 4.85 & 8.5 \\ 1976 & 4.92 & 7.7\end{array}$

Comparing these figures to those in Diagram 1 it should be clear that the profit rate in the 1970's has been abnormally low. With this rate around $4.9 \%$ and the unemployment rate in 1978-1979 going down to the $5.8 \%$ range, the rate of inflation due to low profitability remains around $2.03 \%$ which constitutes some $40 \%$ of total domestic value added inflation in the 1970's excluding the extraordinary years of 1974-1975. 
This means that as long as the profit rate remains abnormally low the basic inflationary pressures will persist and be intensified by a public policy to expand demand in order to lower the unemployment rate. The converse of this observation is equally clear: any public policy aiming to reduce inflation will not be successful unless it is also directed towards raising the profit rate on private capital. For this same reason no compulsory price control program can reduce inflation if it prevents the profit rate from rising. We expect to study other policy implications of this theory after a further study of the "feedback inflation" mentioned earlier. 
Appendix

(I) The key variables of this study will be listed below and a brief reference to the data sources will be made. $Y(t)$ : Real GNP: for 1909-1928; The Economic Almanac, the Conference Board 1960.

for 1929-1972; National Income and Product Accounts. of the United States 1929-1974, B.E.A., 1975

for 1973-1977; The Economic Report of the President, !1978. $P(t)$ : the GN Deflator: for 1909-1928; Long Term Economic Growth, Census Bureau, 1965, series B62.

for 1929-1945; Long Term Economic Growth, Census Bureau, 1965, series B63.

for 1946-1972; Economic Report of the President, 1976.

for 1973-1977; Economic Report of the President, 1978.

$W(t) L(t)$ : Labor Income Before Taxes was calculated by adding total compensation to employees and the imputed labor component of self employed.

For the direct compensation 1909-1928; D. Creamer [1956], Table Al, page 116. 1929-1972; National Income and Product Accounts of the United States 1929-1974, B.E.A. 1975 .

1973 ; Survey of Current Business, July 1977.
1974-1977;
$"$
$"$
$"$, July 1978. 
For the Self Employed Component we imputed the mean rate of compensation for the employed. The data for the number of self employed was obtained from

1909-1928; D. Creamer [1956], Table Bl-B, pp. 131-132. 1929-1965; National Income and Product Accounts of the United States 1929-1965, OBE, 1966.

1966-1973; Survey of Current Business, July 1970, 1976. 1974-1977; our calculations. Data available on request. $L(t)$ : Total Labor Employed. Total number of persons engaged in production multiplied by the number of weekly hours. For the number of persons engaged use exactly the same sources as provided above. For the weekly rate of hours worked an analytical procedure was devised which integrated the following sources:

1909-19.53; Long Term Economic Growth, 1965, Series B6.

1954-1965; " " " " " B7.

1966-1974; BLS, Earnings and Employment in the U.S. 1969-1975. 1975-1977; Monthly Labor Review, B.L.S., Department of Labor, October 1978 .

$U(t)$ : Unemployment Rate:

1909-1930; Historical Statistics of the U.S., Census Bureau, 1976. 1931-1943; Darby, M. [1976].

1944-1970; Historical Statistics of the U.S., Census Bureau, 1976. 1971-1974; The Economic Report of the President, 1976.

1975-1977; B.I.S., Monthly Labor Review, October 1978. 
$\underline{P}_{k}(t) K(t), K(t):$ The Nominal and Real Capital Stock. An analytical procedure was applied to synthesize information from the following sources:

Goldsmith, R. [1975]

Survey of Current Business: December 1972, April 1976, September 1978

Economic Report of the President, 1978

Tice, H. S. [1967]

Kendrick, J. W. [1976]

Construction Review, Department of Commerce, November 1978

The final data appears at the end of this appendix.

$\underline{P}_{\operatorname{Im}}(t) \operatorname{Im}(t):$ Nominal Value of Imports

1909-1970: Historical Statistics of the U.S., 1976, Series U219. 1971-1977; Economic Report of the President, 1978.

$\underline{P}_{\operatorname{Im}}(t):$ Index of Import Prices

1909-1970; Historical Statistics of the U.S. 1976.

1971-1977; Survey of Current Business, various issues.

$\tau(t):$ The Average Tax Rate. This variable measures the ratio of total taxes paid by all economic agents to GNP. Due to the complexity of all the sources used for the different taxes a detail description all these public sources will be omitted. The actual data used will appear below.

(II) The Independent Variables Used in the First Stage

(1) \% of U.S. population under 18 years of age

(2) \% of labor force unionized 
(3) Length of time since the bottom of previous recession

(4) \% change in import prices

(5) Educational attainment: mean number of years completed, Males 25-64

(6) Value of imports

(7) The capital labor ratio

(8) The participation rate

(9) The mean number of weekly hours of work

(10) Real per-capita wealth (including the government debt held by by the public)

(11) Time

(12) \% of the population residing in cities with 100,000 or more

(13) A variable measuring the distribution of wealth

(14) The other exogenous variables appearing in equation (4.3) in the text.

\section{(III) Special Data Tables}

As noted above some variables were either constructed by us or significant analytical work was performed in their construction. These we provide directly 


\begin{tabular}{|c|c|c|c|c|}
\hline Year & $\begin{array}{c}K(t) \\
\text { The Gross Real } \\
\text { Capital Stock } \\
\$ \text { Billions } \\
\text { I972 Prices }\end{array}$ & $\begin{array}{l}\mathrm{P}_{\mathbf{k}}(t) \mathrm{K}(\mathrm{t}) \\
\text { The Gross } \\
\text { Nominal } \\
\text { Capital } \\
\text { Stock }\end{array}$ & $\begin{array}{l}r(t) \\
\text { The Gross } \\
\text { Rate of } \\
\text { Return on } \\
\text { Capital }\end{array}$ & $\begin{array}{l}\text { T(t) } \\
\text { The Mean } \\
\text { Tax Rate } \\
\text { Out of } \\
\text { GNP }\end{array}$ \\
\hline 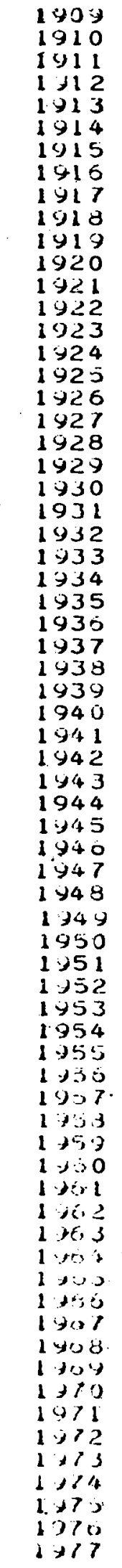 & 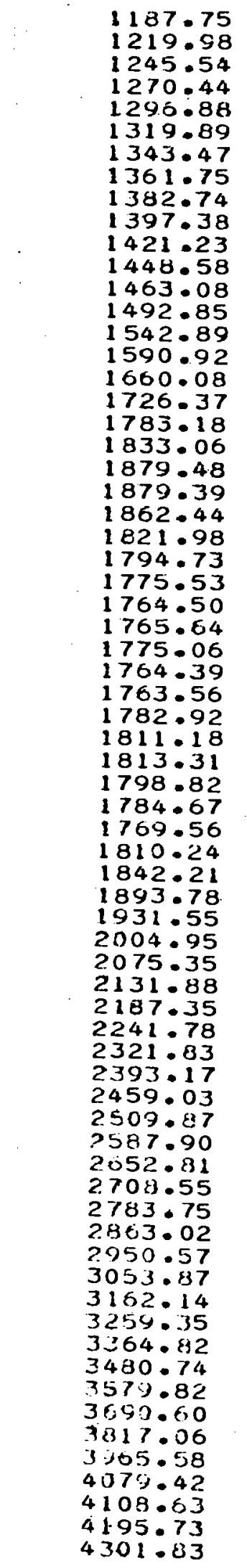 & 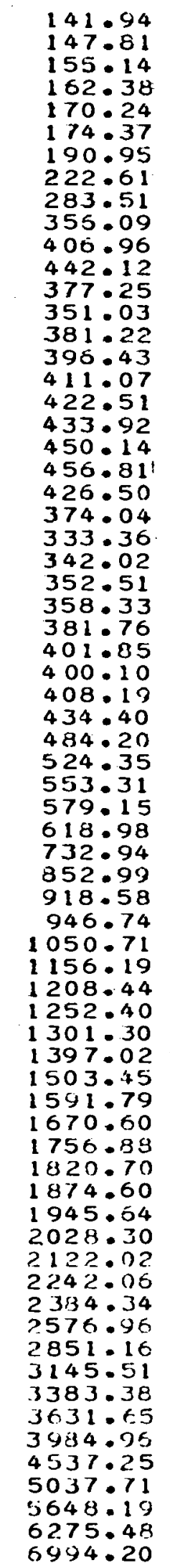 & $\begin{array}{l}0.0710311 \\
0.0633981 \\
0.0537199 \\
0.0526748 \\
0.0513352 \\
0.0469728 \\
0.0596630 \\
0.0762416 \\
0.0976610 \\
0.0980349 \\
0.0776073 \\
0.0593931 \\
0.0492788 \\
0.0464258 \\
0.0574246 \\
0.0548589 \\
0.0557538 \\
0.0603845 \\
0.0550969 \\
0.0528220 \\
0.0607732 \\
0.0526321 \\
0.0433573 \\
0.0270927 \\
0.0246344 \\
0.0323269 \\
0.0383520 \\
0.0428392 \\
0.0430776 \\
0.0413190 \\
0.0439655 \\
0.0461260 \\
0.0483211 \\
0.0597262 \\
0.0698775 \\
0.0801124 \\
0.0750518 \\
0.0520068 \\
0.0490589 \\
0.0553948 \\
0.0540054 \\
0.0517555 \\
0.0541792 \\
0.0522255 \\
0.0509079 \\
0.0520941 \\
0.0541358 \\
0.0600305 \\
0.0498152 \\
0.0505429 \\
0.0509120 \\
0.0498945 \\
0.0503416 \\
0.0547267 \\
0.0550507 \\
0.0563339 \\
0.0593158 \\
0.0615956 \\
0.0583378 \\
0.0537171 \\
0.0491173 \\
0.0464400 \\
0.0485605 \\
0.0493918 \\
0.0491536 \\
0.0457511 \\
0.0485139 \\
0.0492248 \\
0.0487531\end{array}$ & 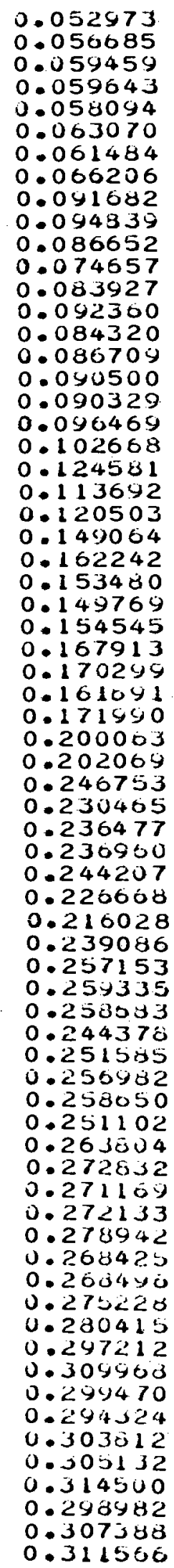 \\
\hline
\end{tabular}




\section{Footnotes}

1) We are using the example of Perry [1966] equations (5.2)-(5.3). More accurately Perry identifies $p(t)$ with the consumer price index $p_{c}(t)$ and writes his price subsystem as follows:

(5.2) $\frac{\dot{p}_{c}(t)}{p_{c}(t)}=b_{0}+b_{1} \frac{\dot{p}^{m}(t-1)}{p^{m}(t-1)}+b_{2} \frac{\dot{p}^{s}(t)}{p^{s}(t)}+b_{3} \frac{\dot{p}^{f}(t)}{p^{f}(t)}$

(5.3) $\frac{\dot{p}^{m}(t)}{p^{m}(t)}=a_{0}+d_{1} \frac{\dot{w}(t)}{w(t)}+d_{2} \frac{\dot{p}^{r}(t)}{p^{r}(t)}+d_{3}\left(\frac{Q(t)}{K(t)}\right)+d_{y} \Delta\left(\frac{Q(t)}{K(t)}\right)$

where

$$
\begin{aligned}
& p^{m}(t)=\text { price of manufactured goods at } t \\
& p^{S}(t)=\text { price of services at } t \\
& p^{f}(t)=\text { price of raw foods at } t \\
& p^{r}(t)=\text { price of raw materials at } t \\
& \frac{Q(t)}{K(t)}=\text { index of capacity utilization at } t .
\end{aligned}
$$

2f This is also the point made by Samuelson-Solow [1960].

3/ This same fact is true in a general competitive economy with a continuum of agents who are small, but with a finite number of firms.

4/ Clearly the most important punishment is the withdrawal of the gain once it has been attained. Here we mean punishment above and beyond that.

5/ The distinction between $r$ and $R$ will be clarified later. Here $r$ is defined as the after tax aggregate profits divided by the nominal value of the aggregate capital stock.

6f Clearly for all prices below $p *(t)$ the demand elasticity is less than 1 .

If It is significant in the "net" equation 2. 


\section{References}

Ashenfelter, O.C., G.E. Johnson and J.H. Pencavel [1972], "Trade Unions and the Rate of Change of Money Wages in United States Manufacturing Industry," The Review of Economic Studies, Vol. XXXIX, No. 1, January, pp. 27-54.

Aumann, R.J. [1959], "Acceptable Points in General Cooperative n-Person Games," in A.W. Tucker and R.D. Luce (eds.), Contributions to the Theory of Games, IV, Annals of Mathematical Studies, No. 4, New Jersey: Princeton University Press, pp. 287-324.

Azariadis, C. [1975], "Implicit Contracts and Underemployment Equilibria," Journal of Political Economy, Vol. 83, pp. 1183-1202.

Azariadis, C. [1978], "Stochastic Disequilibrium in a Labor Contracts Economy," in G. Schwodiauer (ed.), Equilibrium and Disequilibrium in Economic Theory, Holland: D. Reidel Publishing, pp. 651-669.

Baily, M.N. [1974], "Wages and Employment Under Uncertain Demand," Review of Economic Studies, Vol. 41, pp. 37-50.

Creamer, D. B. [1956], Personal Income during Business Cycles, NBER Studies in Business Cycles, No. 6, New Jersey: Princeton.

Darby, M.R. [1976], "Three-and-a-half Million U.S. Employees Have Been Mislaid; or, an Explanation of Unemployment, 1934-1941," Journal of Political Economy, 84, February, pp. 1-17.

Eckstein, 0. [1964], "A Theory of the Wage-Price Process in Modern Industry," The Review of Economic Studies, Vol. 31, (4), No. 88, October, pp. 267-286.

Eckstein, O. and T.A. Wilson [1962], "The Determination of Money Wages in American Industry," Quarterly Journal of Economics, No. 305, August, pp. 379-414.

Fair, R. C. [1970], "The Estimation of Simultaneous Equation Models with Lagged Endogenous Variables and First-Order Serially Correlated Errors," Econometrica, Vol. 38, No. 3, May, pp. 507-517. 
Feldstein, M. and L. Summers [1977], "Is the Rate of Profit Falling," Brookings Papers of Economic Activity, Vol. 4, pp. 2ll-228.

Friedman, M. [1970], "A Theoretical Framework for Monetary Analysis," Journal of Political Economy, Vol. 78, March/April, pp. 193238.

Friedman, M. [1971], "A Monetary Theory of Nominal Income," Journal of Political Economy, Vol. 79, March/April, pp. 323-337.

Gerard-Varet, L. A and H. Moulin [1978], "Correlation and Duopoly," Journal of Economic Theory, Vol. 19, No. 1, pp. 123-149.

Goldsmith, R. W. [1955], A Study of Saving in the United States, New Jersey: Princeton.

Gordon, D.F. [1974], "A Neo-Classical Theory of Keynesian Unemployment," Economic Inquiry, Vol. 12, pp. 431-459.

Gordon, R.J. [1975], "The Impact of Aggregate Demand on Prices," Brookings Papers of Economic Activity, Vol. 3, pp. 613-670.

Gordon, R.J. [1976], "Recent Developments in the Theory of Inflation and Unemployment," Journal of Monetary Economics, Vol. 2, April, pp. 185-219.

Kendrick, J.W.[1976], The National Wealth of the United States, The Conference Board, New York, N.Y.

Kurz, M. [1977], "Altruistic Equilibrium," Economics Progress Private Values and Public Policy, Essays in honor of William Fellner, B. Belassa, and R. Nelson (eds.), Amsterdam: North-Holland, pp. $177-200$.

Lipsey, R.G. [1960], "The Relation Between Unemployment and the Rate of Change of Money Wage Rates in the United Kingdom, 1862-1957: A Further Analysis," Economica, Vol. 27, February, pp. 1-31.

Lipsey, R.G. [1963], An Introduction to Positive Economics, Appendix to Chapter 33, Weidenfeld and Nicolson.

Lipsey, R.G. and M.D. Steuer [1961], "The Relation Between Profits and Wage Rates," Economica, May.

Lucas, R.E. and L.A. Rapping [1969], "Real Wages Employment and the Price Level," Journal of Political Economy, Vol. 77 , September/October, pp. 721-754. 
Lucas, R.E. and L.A. Rapping [1972], "Unemployment in the Great Depression: Is There a Full Explanation?," Journal of Political Economy, Vol. 80, January/February, pp. 186-191.

Modigliani, F. [1958], "New Development on the Oligopoly Front," Journal of Political Economy, Vol. 66, June, pp. 215-233.

Modigliani, F. [1977], "The Monetary Controversy or, Should we Forsake Stabilization Policies," American Economic Review, Vol. 67, No. 2, March, pp. 1-19.

Nordhaus, W.D. [1974], "The Falling Share of Profits," Brookings Papers on Economic Activity, Vol. 1, pp. 169-217.

Patinkin, D. [1956], Money, Interest and Prices, Harper and Row, New York.

Perry, G.L. [1964], "The Determinants of Wage Rate Changes," Review of Economic Studies, Vol. 31 , (4), No. 88, October, pp. 287308 .

Perry, G.L. [1966], Unemployment Money Wage Rates and Inflation, M.I.T. Press.

Phillips, A.W. [1958], "The Relation Between Unemployment and the Rate of Change of Money Wage Rates in the United Kingdom, 1861-1957," Economica, Vol. 25, November, pp. 283-299.

Samuelson, P.A. and R.M. Solow [1960], "Analytical Aspects of Anti-Inflation Policy," American Economic Review, Papers and Proceedings, Vol. 50, May, pp. 177-194.

Sims, C.A. [1972], "Money Income and Causality," American Economic Review, Vol. 62, No. 4, September, pp. 540-552.

Tice, H. S. [1967], Depreciation, Obsolescence, and the Measurement of the Aggregate Capital Stock of the United States 1900-1962, Appendix D (unpublished dissertation, Yale University).

Tobin, J. [1972], "Friedman's Theoretical Framework," Journal of Political Economy, Vol. 80, No. 5, September/October, pp. 852-863. 